\title{
, \\ Suberin Biosynthesis, Assembly, and Regulation
}

\author{
Kathlyn N. Woolfson, Mina Esfandiari and Mark A. Bernards *(D)
}

check for updates

Citation: Woolfson, K.N.; Esfandiari, M.; Bernards, M.A. Suberin

Biosynthesis, Assembly, and

Regulation. Plants 2022, 11, 555

https://doi.org/10.3390/

plants11040555

Academic Editor: Idit Ginzberg

Received: 29 January 2022

Accepted: 16 February 2022

Published: 19 February 2022

Publisher's Note: MDPI stays neutral with regard to jurisdictional claims in published maps and institutional affiliations.

Copyright: (c) 2022 by the authors. Licensee MDPI, Basel, Switzerland. This article is an open access article distributed under the terms and conditions of the Creative Commons Attribution (CC BY) license (https:/ / creativecommons.org/licenses/by/ $4.0 /)$.

\author{
Department of Biology, Western University, London, ON N6A 5B7, Canada; kwoolfso@uwo.ca (K.N.W.); \\ mesfand2@uwo.ca (M.E.) \\ * Correspondence: bernards@uwo.ca
}

\begin{abstract}
Suberin is a specialized cell wall modifying polymer comprising both phenolic-derived and fatty acid-derived monomers, which is deposited in below-ground dermal tissues (epidermis, endodermis, periderm) and above-ground periderm (i.e., bark). Suberized cells are largely impermeable to water and provide a critical protective layer preventing water loss and pathogen infection. The deposition of suberin is part of the skin maturation process of important tuber crops such as potato and can affect storage longevity. Historically, the term "suberin" has been used to describe a polyester of largely aliphatic monomers (fatty acids, $\omega$-hydroxy fatty acids, $\alpha, \omega$-dioic acids, 1alkanols), hydroxycinnamic acids, and glycerol. However, exhaustive alkaline hydrolysis, which removes esterified aliphatics and phenolics from suberized tissue, reveals a core poly(phenolic) macromolecule, the depolymerization of which yields phenolics not found in the aliphatic polyester. Time course analysis of suberin deposition, at both the transcriptional and metabolite levels, supports a temporal regulation of suberin deposition, with phenolics being polymerized into a poly(phenolic) domain in advance of the bulk of the poly(aliphatics) that characterize suberized cells. In the present review, we summarize the literature describing suberin monomer biosynthesis and speculate on aspects of suberin assembly. In addition, we highlight recent advances in our understanding of how suberization may be regulated, including at the phytohormone, transcription factor, and protein scaffold levels.
\end{abstract}

Keywords: suberin; abscisic acid; transcription factors; CASP proteins; phenylpropanoid metabolism; fatty acid metabolism; macromolecular assembly

\section{Introduction}

Plants have developed effective processes to facilitate their survival, including the production of secondary metabolites [1,2]. The bioactivities of these metabolites involve regulating plant growth, and enabling plants to cope with stressful conditions including biotic threats and environmental hazards [3]. Suberin is a specialized cell wall modifying polymer comprising phenolic and aliphatic compounds derived from phenylpropanoid and fatty acid pathways, respectively, reviewed in [4]. Suberin deposition occurs in two ways: (1) during normal growth in the endodermis and epidermis of roots, bark, seed coats, and specialized organs such as tubers, and (2) in response to wounding stress $[5,6]$. Suberin is developmentally deposited in the cell walls of root epidermal, exodermal, and endodermal cells in association with the Casparian strip (CS). As a product of secondary metabolism, suberin is regulated and deposited in a tissue-specific manner [7].

The genomic resources of model organisms such as Arabidopsis thaliana and the crop potato (Solanum tuberosum L.) have provided opportunities to elucidate the function of numerous suberin biosynthetic genes [8,9]. Molecular genetic approaches and mutant analyses have led to the identification and characterization of several genes encoding enzymes involved in suberin biosynthesis including: $\beta$-ketoacyl-CoA synthase genes StKCS6 [10], AtKCS2, and AtKCS20 [11,12] encoding enzymes that generate very-long-chain fatty acids, genes encoding cytochrome $\mathrm{P} 450$ oxidases required for $\omega$-hydroxy acid biosynthesis, StCYP86A33 [13,14], AtCYP86A1 [15], and AtCYP86B1 [16,17], three fatty acyl-CoA reductase 
genes, AtFAR1, AtFAR4, and AtFAR5, involved in the production of different chain-length primary fatty alcohols $[18,19]$, a glycerol-3-phosphate acyltransferase involved in the synthesis of monoacylglycerol esters encoded by AtGPAT5 [20,21], aliphatic suberin feruloyl transferases that transfer from feruloyl-CoA to $\omega$-hydroxy acids and fatty alcohols, encoded by StFHT and AtASFT [17,22-24], and genes encoding the ATP-binding cassette G-subfamily transporters StABCG1 [25], AtABCG2, AtABCG6, and AtABCG20 [26]. Since many of the characterized suberin biosynthetic enzymes and their encoding genes exhibit conserved functionality across species, studies in different plant systems are often relevant and applicable to other plant species.

In the last two decades, advances in our understanding of suberin biosynthesis and deposition, and how these processes are controlled, have highlighted regulatory roles for phytohormones, transcription factors (TF), and Casparian strip membrane domain proteins (CASPs). This review provides an overview of the current state of knowledge of suberin monomer biosynthesis, the assembly of monomers into the suberin macromolecule, and the coordination of suberin deposition by phytohormones, TFs and CASPs. An increased fundamental understanding of the role of suberin in response to various stressors, and of the mechanisms that regulate the suberization process, may have important implications for crop improvement efforts, including enhanced tuber storage and resistance to drought stress and pathogen infection [27].

\section{The Suberin Enigma}

Suberin has been differentially described in the literature as a polyester-based aliphatic polymer with associated phenolics (i.e., an integrated model), and as a polymer comprising distinct poly(aliphatic) and poly(phenolic) domains (i.e., a two-domain model). These two views of suberin are based on the knowledge that suberized tissue contains both poly(phenolic) and poly(aliphatic) polymers, but for which the structures are unresolved. The integrated model of suberin structure, originally proposed by Kolattukudy [28], and further refined by Graça [29] depicts a polymer with alternating phenolic and aliphatic polymer layers (Figure 1), inspired by the characteristic lamellar bands observed in TEM micrographs, and supported by numerous lines of evidence, reviewed in [29]. For example, partial depolymerization of suberin yields fragments containing both aliphatic and phenolic compounds, linked via esters of glycerol [29]. In this integrated model, "suberin" refers to a largely poly(aliphatic) polymer with associated phenolics. However, complete removal of the aliphatic components yields a poly(phenolic) rich residue [30] that contains phenolic monomers (e.g., sinapic acid-derived phenolics) not found in the aliphatic portion of the polymer. Additional physical data (solid state ${ }^{13} \mathrm{C}-\mathrm{NMR}$ [31] and scanning differential calorimetry [30]) supports the two-domain model in which "suberin" refers to a macromolecule with two distinct, but covalently linked domains (Figure 1) [4]. One domain is anchored in the primary cell wall and consists of polymerized phenolic compounds, which is referred to as the suberin poly(phenolic) domain (SPPD) [32-34]. The other domain, referred to as the suberin poly(aliphatic) domain (SPAD), spans the space between the cell wall and plasma membrane, and is made up of fatty acid-derived aliphatic constituents, as well as associated phenolics. The two-domain model is further supported by (1) metabolic [35] and gene expression [36,37] data demonstrating a temporal difference in phenolic and aliphatic metabolism during induced suberization, (2) the presence of both phenolic and aliphatic components in ectopically deposited suberin [38], and (3) the failure of suberin deposition in endodermal tissue with compromised phenylpropanoid metabolism [39]. The models are not mutually exclusive, however, and differ mainly in the degree of integration of the phenolic and aliphatic components into "suberin". Either way, both phenolic and aliphatic metabolism are involved in the biosynthesis and assembly of the suberin in suberized tissues. To complicate matters, recent claims about Casparian strip (CS) composition [40] have questioned the essential composition of suberin, leading the authors to suggest both that (aliphatic) suberin is not essential to CS function, and that poly(phenolics) are not part of "suberin". However, it can be argued that the data 
presented in [40] more strongly support a two-domain model of suberin than refute it and reflect a developmental sequence in which phenolics are laid down in the CS in advance of aliphatics. Indeed, more recent data from the same group noted above [39] convincingly demonstrates that when phenolic biosynthesis is impaired during CS formation, suberin lamellae are not deposited in later stages of endodermal development [39]. Altogether, there are many independent lines of evidence supporting a critical role for poly(phenolics) in the overall suberin macromolecular structure.

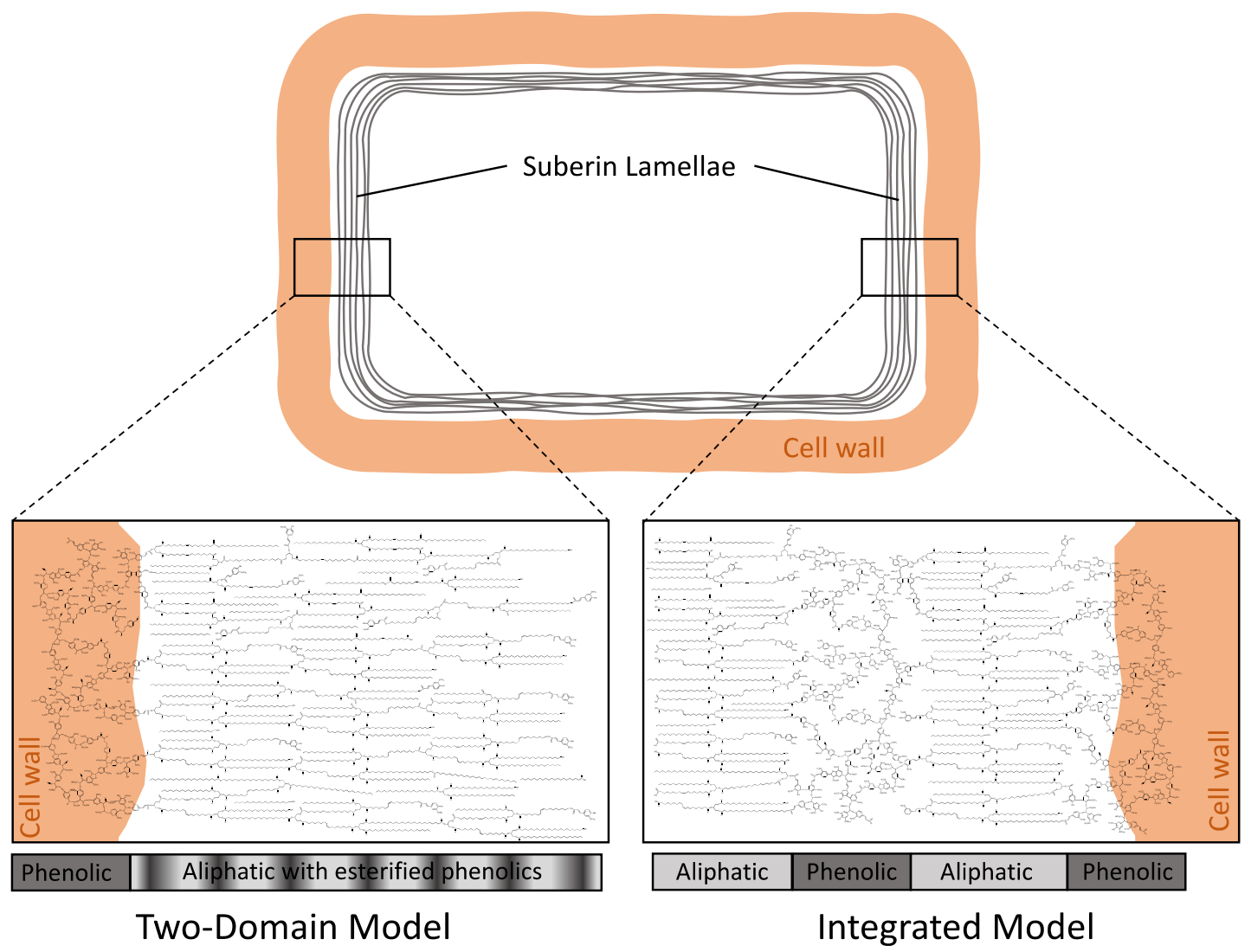

Figure 1. Comparison of two models of suberin structure. Two models of suberin structure are presented: a two-domain model based on [4] and an integrated model based on [29]. In each case, both phenolic and aliphatic polymers are depicted. The poly(phenolics) are shown as cross-linked by $\mathrm{C}-\mathrm{C}$ and $\mathrm{C}-\mathrm{O}-\mathrm{C}$ bonds, while the poly(aliphatics) are shown as polyesters cross-linked via glycerol. In the two-domain model, the poly(phenolic) domain is envisioned as integrated into the cell wall, and esterified to the poly(aliphatic) domain via glycerol esters. The characteristic lamellae of suberized cells are proposed to arise from variation in electron density moving through less dense hydrocarbon and more dense areas rich in ester linkages and phenolics. By contrast, the integrated model is shown as repeating layers of poly(phenolic) and poly(aliphatic) components, that give rise to the characteristic lamellae. The degree to which the integrated model is embedded into the cell wall, or how tightly the two polymer types are cross-linked, remains unknown. Several lines of evidence support both models; further targeted experimentation will be required to determine whether one or both exist, or indeed a different arrangement comprises suberin.

Regardless of which structural model accurately represents the structure of suberin, the poly(phenolics) consist of polymerized hydroxycinnamic acids and their derivatives, tyramine-derived hydroxycinnamic acid amides (at least in potato), and a small proportion of hydroxycinnamyl alcohols, i.e., monolignols (Figure 2) [32-34]. By contrast, the poly(aliphatics) are made up of fatty acid-derived aliphatic constituents including verylong-chain (C24 to C32) 1-alkanols, bifunctional $\omega$-hydroxyalkanoic acids, and $\alpha, \omega$-dioic acids, as well as shorter C18:1 oxidized fatty acids, and non-polymerized (i.e., soluble) 
associated waxes including alkyl hydroxycinnamate esters, 1-alkanols, fatty acids, and alkanes [41-43]. Glycerol and esterified hydroxycinnamic acids are also present amongst the poly(aliphatics) [44-46]. The SPAD monomers are cross-linked by glycerol bridges to yield a three-dimensional polyester. While monomers in the SPPD are also cross-linked, these are mediated via inter-unit $\mathrm{C}-\mathrm{C}$ and ether linkages, rather than ester bonds [4,32]. Evidence supports a likely role for glycerol in linking the SPPD to the SPAD [47-49]. Suberized tissues in different species contain varying proportions of these compounds, though $\omega$-hydroxy fatty acids and dioic acids predominate. See for example $[29,41,50,51]$.

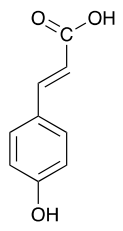

$\mathrm{p}$-Coumaric Acid

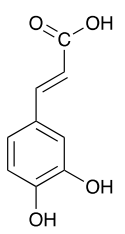

Caffeic Acid

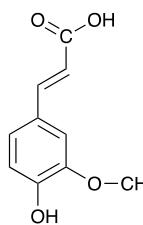

Ferulic Acid

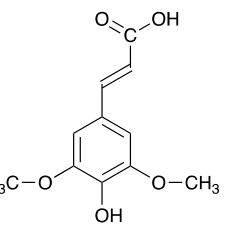

Sinapic Acid<smiles>COc1cc(/C=C/C(=O)NCCc2ccc(O)cc2)ccc1O</smiles>

Feruloyl tyramine<smiles>OCCc1ccc(O)cc1</smiles>

p-Coumaryl
Alcohol<smiles>COc1cc(/C=C/CO)ccc1O</smiles><smiles>COc1cc(/C=C/CO)cc(OC)c1O</smiles>

Guaiacyl
Alcohol Sinapyl
Alcohol

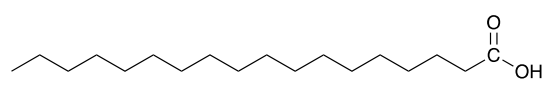

Fatty acids

Homologous Series (C18-C30)

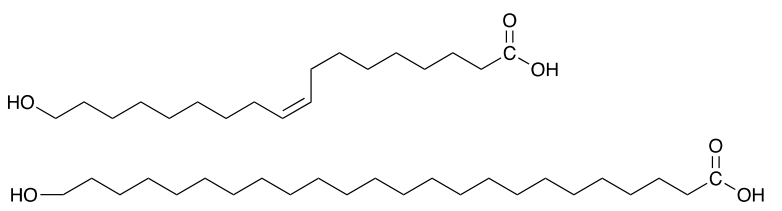

w-OH-Fatty acids

Homologous Series (C18:1; C22-C30)<smiles>O=C(O)CCCCCCCCCCCCCCCCCC(=O)O</smiles><smiles>O=C(O)CCCCCCCCCCCCCCCCCCCCCCC(=O)O</smiles>

a,w-Dioic acids

Homologous Series (C18:1; C22-C30)

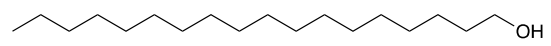

Fatty alcohols
Homologous Series (C18:1; C22-C30)

Figure 2. Typical suberin phenolic and aliphatic monomers. 


\section{Suberin Biosynthesis and Assembly}

Over the last twenty years, many biosynthetic steps required for suberin production have been elucidated. Generally, characterization has focused on steps from two biosynthetic pathways implicated in phenolic and aliphatic monomer production required for the assembly of the respective poly(phenolic) and poly(aliphatic) suberin domains, while novel aspects of linkage and assembly have also been recently elucidated. Table 1 provides a compilation of relevant genes described below.

Table 1. Key suberin biosynthetic pathway and assembly steps.

\begin{tabular}{|c|c|c|c|}
\hline Gene & Corresponding Enzyme Function $^{1}$ & Plant Species $^{2}$ & Reference $^{3}$ \\
\hline \multicolumn{4}{|c|}{ Biosynthesis of phenolic monomers: Phenylpropanoid metabolism } \\
\hline$P A L$ & Phenylalanine ammonia-lyase & Multiple & [52] \\
\hline $\mathrm{C} 4 \mathrm{H}$ & Cinnamic acid 4-hydroxylase $(\mathrm{C} 4 \mathrm{H})$ & Multiple & [53] \\
\hline $4 C L$ & 4-Coumarate-CoA ligase & Multiple & [54] \\
\hline HCT & Hydroxycinnamoyl-CoA transferase & Multiple & [55] \\
\hline$C 3^{\prime} H$ & p-Coumaroyl-quinate-shikimate $3^{\prime}$-hydroxylase & Multiple & [56] \\
\hline CСOAOMT & Caffeoyl-CoA-O-methyltransferase & Multiple & [57] \\
\hline F5H & Ferulate 5-hydroxlyase & Multiple & [58] \\
\hline COMT & Caffeic acid O-methyltransferase & Multiple & [59] \\
\hline THT & $\begin{array}{l}\text { Hydroxycinnamoyl-CoA:tyramine } \\
\text { N-(hydroxycinnamoyl) transferase }\end{array}$ & Solanum tuberosum & {$[60]$} \\
\hline$C C R$ & Cinnamoyl-CoA reductase & Multiple & [61] \\
\hline$C A D$ & Cinnamyl alcohol dehydrogenase & Multiple & [32] \\
\hline \multicolumn{4}{|c|}{ Assembly of the suberin poly(phenolic) domain } \\
\hline PRX & Suberization-associated anionic peroxidase & Solanum tuberosum & [62] \\
\hline RBOHF & Respiratory burst oxidase homolog F NADPH oxidases & Solanum tuberosum, Arabidopsis thaliana & [63-65] \\
\hline PER64 & Peroxidase & Arabidopsis thaliana & {$[66]$} \\
\hline ESB1 & Dirigent-like protein & Arabidopsis thaliana & [67] \\
\hline TPX1 & Cationic peroxidase & Solanum lycopersicum & {$[68,69]$} \\
\hline \multicolumn{4}{|c|}{ Biosynthesis of aliphatic monomers: Fatty acid elongation, oxidation, and reduction } \\
\hline KCS2/DAISY & $\beta$-ketoacyl-CoA synthase & Arabidopsis thaliana & [70] \\
\hline KCS20 & $\beta$-ketoacyl-CoA synthase & Arabidopsis thaliana & [12] \\
\hline KCS6 & $\beta$-ketoacyl-CoA synthase & Solanum tuberosum & [10] \\
\hline KCR1 & $\beta$-ketoacyl-CoA reductase & Arabidopsis thaliana & [71] \\
\hline $\begin{array}{l}\text { PASTICCINO2 } \\
\text { (PAS2) }\end{array}$ & 3-Hydroxyacyl-CoA dehydratase & Arabidopsis thaliana & [72] \\
\hline$E C R$ & Enoyl-CoA reductase ${ }^{4}$ & Arabidopsis thaliana & [73] \\
\hline CYP86A1/HORST & Cytochrome P450-dependent fatty acid $\omega$-hydroxylase & Arabidopsis thaliana & {$[15,74]$} \\
\hline CYP86B1/RALPH & Cytochrome P450-dependent fatty acid $\omega$-hydroxylase & Arabidopsis thaliana & [16] \\
\hline CYP86A33 & Cytochrome P450-dependent fatty acid $\omega$-hydroxylase & Solanum tuberosum & {$[13,14]$} \\
\hline CYP86B12 & Cytochrome P450-dependent fatty acid $\omega$-hydroxylase & Solanum tuberosum ${ }^{4}$ & {$[36]$} \\
\hline NHFAD ${ }^{4}$ & $\begin{array}{c}\text { NADP-dependent } \omega \text {-hydroxy fatty } \\
\text { acid dehydrogenase }\end{array}$ & Solanum tuberosum & [75-77] \\
\hline NOFAD ${ }^{4}$ & NADP-dependent $\omega$-oxo fatty acid dehydrogenase & Solanum tuberosum & [75-77] \\
\hline СYP94A5 & Cytochrome P450-dependent fatty acid hydroxylase & Nicotiana tabacum & [78] \\
\hline CYP94C1 & Cytochrome P450-dependent fatty acid hydroxylase & Arabidopsis thaliana & [79] \\
\hline FAR1 & Fatty acyl-CoA reductase & Arabidopsis thaliana & [18] \\
\hline FAR3 & Fatty acyl-CoA reductase & Solanum tuberosum ${ }^{4}$ & [36] \\
\hline FAR4 & Fatty acyl-CoA reductase & Arabidopsis thaliana & [18] \\
\hline FAR5 & Fatty acyl-CoA reductase & Arabidopsis thaliana & [18] \\
\hline $\begin{array}{c}\text { ECERIFERUM1 } \\
\text { (CER1) }\end{array}$ & Very-long-chain aldehyde decarbonylase & Arabidopsis thaliana & [80] \\
\hline $\begin{array}{l}\text { ECERIFERUM3 } \\
\text { (CER3) }\end{array}$ & Very-long-chain aldehyde decarbonylase & Arabidopsis thaliana & [80] \\
\hline CYTB5 & Cytochrome $b_{5}$ hemoprotein (cofactor) & Arabidopsis thaliana & [80] \\
\hline LACS1 & Long-chain acyl-CoA synthase & Arabidopsis thaliana & [2] \\
\hline
\end{tabular}


Table 1. Cont.

\begin{tabular}{|c|c|c|c|}
\hline Gene & Corresponding Enzyme Function ${ }^{1}$ & Plant Species ${ }^{2}$ & Reference $^{3}$ \\
\hline \multicolumn{4}{|c|}{ Esterification, deposition, and assembly of the suberin poly(aliphatic) domain } \\
\hline GPAT5 & Glycerol-3-phosphate acyltransferase & Arabidopsis thaliana, Solanum tuberosum ${ }^{4}$ & $\begin{array}{c}{[20,21]} \\
{[36]}\end{array}$ \\
\hline GPAT6 & Glycerol-3-phosphate acyltransferase & Solanum tuberosum ${ }^{4}$ & [36] \\
\hline GPAT7 & Glycerol-3-phosphate acyltransferase & Arabidopsis thaliana & [81] \\
\hline FHT & $\begin{array}{l}\text { Fatty alcohol/fatty } \omega \text {-hydroxyacid } \\
\text { hydroxycinnamoyl acyltransferase }\end{array}$ & Solanum tuberosum & {$[23,24]$} \\
\hline ASFT/HHT & $\begin{array}{c}\text { Feruloyl transferase / } \omega \text {-hydroxy acid } \\
\text { hydroxycinnamoyltransferase }\end{array}$ & Arabidopsis thaliana & {$[17,22]$} \\
\hline$A B C G 1$ & ATP-binding cassette subfamily G transporter & Solanum tuberosum, Arabidopsis thaliana & {$[25,82]$} \\
\hline ABCG11/WBC11 & ATP-binding cassette subfamily G transporter & Arabidopsis thaliana, Solanum tuberosum ${ }^{4}$ & {$[82,83]$} \\
\hline$A B C G 2$ & ATP-binding cassette subfamily G transporter & Arabidopsis thaliana & [26] \\
\hline$A B G 6$ & ATP-binding cassette subfamily G transporter & Arabidopsis thaliana & [26] \\
\hline ABCG20 & ATP-binding cassette subfamily G transporter & Arabidopsis thaliana & [26] \\
\hline RCN1/ABCG5 & ATP-binding cassette subfamily G transporter & Oryza sativa & [84] \\
\hline SUS & Suberin synthase / GDSL-motif esterase ${ }^{4}$ & Multiple & [85] \\
\hline CASP1-like/CASP8 & Casparian strip membrane domain-like protein ${ }^{4}$ & Solanum tuberosum & {$[86]$} \\
\hline $\begin{array}{l}\text { CASP1B2- } \\
\text { like/CASP9 }\end{array}$ & Casparian strip membrane domain-like protein 4 & Solanum tuberosum & {$[86]$} \\
\hline CASPL1B2 & Casparian strip membrane domain-like protein ${ }^{4}$ & Arabidopsis thaliana & [85] \\
\hline
\end{tabular}

${ }^{1}$ Includes known and predicted functions. ${ }^{2}$ "Multiple" species reflects general knowledge and/or characterization in 3+ species, e.g., based on known conserved lignin biosynthetic steps. Individual species are listed where applicable. ${ }^{3}$ Representative references are given. ${ }^{4}$ Gene and/or enzyme function and involvement in suberization is predicted. Predicted function is based on preliminary characterization (e.g., transcriptomic or proteomic analysis, or identification through experimental observation) and/or putative homology to a counterpart characterized in another species.

Total and relative suberin monomer composition varies between developmental stages, plant organs, and species, but is similar enough $[50,51]$ that diverse plants likely express shared pathways required for suberin production. Loss of function mutants have been used to characterize biosynthetic genes in Arabidopsis that translate well to putative potato orthologs in forward and reverse genetics experiments. For example, a key fatty acid $\omega$-hydroxylase gene AtCYP86A1, encoding a CYP450 required to produce predominant aliphatic suberin monomers, was characterized in Arabidopsis using a cyp86a1/horst mutant [15], and subsequent reverse and forward genetics approaches confirmed the function of its putative potato ortholog StCYP86A33 [13] including functional complementation of the cyp86a1/horst mutant [14].

\subsection{Biosynthesis and Polymerization of Phenolic Monomers}

The chemical composition of the phenolic domain of suberin has not been as thoroughly characterized as that of the aliphatic domain. In potato, which has been most studied in this regard, the SPPD is made up of hydroxycinnamic acids and their derivatives, including hydroxycinnamoyl amides and monolignols (Figure 2), all derived via the phenylpropanoid pathway. This biosynthetic pathway is highly conserved across the plant kingdom and the core pathway is involved in preliminary steps that channel carbon skeletons towards the biosynthesis of many different secondary metabolites, including monomers specific to lignin and the SPPD. The phenylpropanoid biosynthetic pathway is well-established in plants, partly due to its role in lignin biosynthesis. Many steps are common to SPPD biosynthesis.

\subsubsection{Phenylpropanoid Metabolism during Suberization}

Few studies address the involvement of phenylpropanoid metabolism during suberization. This is partly due to the highly localized and cell-specific deposition of suberin, making it technically challenging to distinguish suberin-specific biosynthesis from that of neighboring tissues. In roots for example, during normal growth and development, phenylpropanoid metabolism associated with CS formation can be overshadowed by the disproportionately greater number of phenolic monomers being synthesized and deposited 
in lignifying cells in the adjacent stele. Consequently, several distinct and complementary approaches are used to study phenylpropanoid metabolism during suberization: (1) histochemical analyses (primarily to track deposition), (2) molecular approaches using mutant analysis and/or fluorescent-tagged fusion protein expression, and (3) inducible systems such as wound-healing potato tubers. There are several recent and excellent reviews about phenylpropanoid metabolism, for example with emphasis on metabolome formation [87] and transport systems [88]. Herein, we provide an overview of phenylpropanoid metabolism with the intention of providing context for our later discussion about the regulation of suberin biosynthesis and deposition.

Phenylalanine ammonia-lyase (PAL) catalyzes the first committed step of the phenylpropanoid pathway, converting the shikimate pathway-derived amino acid phenylalanine into cinnamate [52]. The next step, para-hydroxylation by cinnamic acid 4-hydroxylase $(\mathrm{C} 4 \mathrm{H})$, yields 4-hydroxycinnamic acid, i.e., $p$-coumaric acid [53]. After conversion to its acid-thiol derivative by 4-coumarate-CoA ligase (4CL) [54], p-coumaroyl-CoA has several possible metabolic fates. For example, $p$-coumaroyl-CoA can be shunted directly into the flavonoid branch of the phenylpropanoid pathway or serve as a precursor to other branch pathways involving side chain modification (e.g., elongation, conjugation, reduction). An alternative metabolic fate, which, among other end products, channels carbon into suberin monomer formation, involves modification of the $p$-coumaric acid carbon skeleton into other common hydroxycinnamic acids in a series of hydroxylation and methyl-transfer reactions, beginning with the conversion of $p$-coumaroyl-CoA into p-coumaroyl-quinate/shikimate via hydroxycinnamoyl-CoA transferase (HCT) [55]. Hydroxylation at the $3^{\prime}$-position by $p$-coumaroyl-quinate/shikimate $3^{\prime}$-hydroxylase $\left(\mathrm{C}^{\prime} \mathrm{H}\right)$ yields caffeoyl-quinate/shikimate [56], which is then converted into caffeoyl-CoA by HCT. Methylation of caffeoyl-CoA via caffeoyl-CoA-O-methyltransferase (CCoAOMT) yields the 4-hydroxy-3-methoxy-substituted hydroxycinnamate structure of ferulic acid [57], which is common to suberin studied in all plant species to date. Ferulate 5-hydroxylase (F5H) [58], in conjunction with caffeic acid $O$-methyltransferase (COMT) [59] in various species yields the 4-hydroxy-3,5-dimethoxy-substituted hydroxycinnamate structure of sinapic acid. $P$ Coumaric acid, caffeic acid, ferulic acid, and sinapic acid (and their derivatives) are all found in the final suberin poly(phenolic) domain, albeit in a species-specific manner.

In potato tuber suberin, hydroxycinnamoyl amides have been identified as part of the SPPD [60]. These derivatives are formed via tyramine hydroxycinnamoyl transferase (THT)-mediated conjugation of tyramine and octopamine, derived from the decarboxylation of tyrosine (tyrosine decarboxylase; TyDC), with hydroxycinnamoyl-CoAs, principally feruloyl-CoA. This pathway is also implicated in the wound- and pathogen-induced biosynthesis of hydroxycinnamic acid amides in leaves of potato [89] and another Solanaceae species, tobacco (Nicotiana tabacum L.) [90].

Hydroxycinnamoyl-CoA thioesters can be converted into their corresponding monolignols by cinnamoyl-CoA reductase (CCR) [61] and cinnamyl alcohol dehydrogenase (CAD). Since monolignols make up a small proportion of the SPPD in potato periderm [32], and CCR enzyme activity is lower in suberizing potato tubers relative to lignifying Pinus taeda L. cells [91], the monolignol biosynthetic pathway is considered a minor metabolic route for hydroxycinnamoyl-CoAs during tuber suberization [4].

\subsubsection{Assembly of the Suberin Poly(phenolic) Domain}

Historically, the SPPD of suberized tissues has been considered "lignin-like" due to the presence of phenylpropanoid-derived monomers, including monolignols, cross-linked to the cell wall [28]. However, lignin and the SPPD can be distinguished by their main monomer constituents, especially the relatively high proportion of hydroxycinnamates [4,29]. The assumption that the chemical and structural nature of the SPPD is lignin-like has meant that the details of SPPD assembly are limited and only two main suberin systems have been studied in any significant detail: potato tuber periderm and Arabidopsis CS. 
Both the precise localization and mechanics of polymerization are critical for SPPD assembly. Here we focus on the process of polymerization and address recent progress in the coordination of where suberin is deposited in Section 4.4 below. The phenolic domain of suberin was initially proposed to undergo polymerization mediated by peroxidase(s) and $\mathrm{H}_{2} \mathrm{O}_{2}$ over 30 years ago [92], in a process akin to that described for lignification [28,93]. In potato, a suberization-associated anionic peroxidase that preferentially oxidizes hydroxycinnamates over their corresponding alcohols, has been described [62]. The hypothesis that the $\mathrm{H}_{2} \mathrm{O}_{2}$ required for the peroxidase-mediated cross-linking of phenolics is generated by an NAD $(\mathrm{P}) \mathrm{H}$-dependent oxidase system is supported by evidence of reactive oxygen species production via oxidative bursts that occur upon tuber wounding [34,63,64]. Similarly, the precise deposition of the CS poly(phenolic) domain was shown to require the spatial production of reactive oxygen species (ROS) via the activation of the respiratory burst oxidase homolog F (RBOHF) NADPH oxidases [65]. Phenolic polymerization in this system requires the localized action of a peroxidase (AtPER64) [66] and a dirigent-like protein (AtESB1) [67]. The involvement of peroxidases, but not laccases, in CS formation in Arabidopsis roots was recently demonstrated using multiple knock-out mutants [68]. Conversely, a salt stress-inducible cationic peroxidase, SITPX1, has been described in tomato (Solanum lycopersicum L.) as playing a role in the polymerization of lignin and phenolic suberin monomers in roots [69]. These species-specific details highlight the differences in suberin poly(phenolic) domain deposition that exist even in closely related plants.

\subsection{Biosynthesis of Aliphatic Monomers}

The SPAD consists primarily of modified fatty acids, primary alcohols, and glycerol (Figure 2). These are ultimately derived from glycolysis and the tricarboxylic acid cycle, which yield acetyl-CoA for plastid-localized fatty acid biosynthesis [94]. Several downstream modifications of 16:0 and 18:0 fatty acid precursors yield final aliphatic suberin monomers characteristic of the SPAD. These include elongation to long $(\mathrm{C} 20, \mathrm{C} 22)$ and very-long-chain fatty acids (VLCFA; mostly C24-C32), reduction of long and VLCFAs to primary alcohols, and $\omega$-hydroxylation and further oxidation of $\omega$-hydroxy fatty acids to $\alpha, \omega$-dioic acids. Several enzymes that catalyze these modification steps have been identified and characterized in Arabidopsis and/or potato systems [95] (Table 1).

Acyl activation is typically an initial requirement for downstream fatty acid metabolism and is carried out by long-chain acyl-CoA synthetase (LACS) family enzymes prior to cutin monomer biosynthesis [2,96]. Although no LACSs linked to suberin biosynthesis have been described to date [97], acyl activation of final SPAD monomers may precede linkage of modified aliphatic monomers with glycerol.

Chain elongation and oxidation represent two major fatty acid modification routes that yield the predominant aliphatic suberin monomers. Elongated chains can be reduced to form primary alcohols or decarboxylated to form alkanes, while a large proportion of oxidized fatty acids in the SPAD are short chains (especially C18) that have undergone desaturation instead of elongation. However, some elongated fatty acids are also oxidized to yield VLC $\omega$-hydroxy and $\alpha, \omega$-dicarboxylic acids and are found in the SPAD.

\subsubsection{Elongation}

Fatty acid elongation is carried out by endoplasmic reticulum membrane-localized fatty acid elongase (FAE) complexes made up of four enzymes [98]. $\beta$-ketoacyl-CoA synthases (KCS) are elongase complex enzymes that catalyze the condensation of acylCoA with fatty acyl-CoAs, and determine the chain length specificity for each reaction, although single condensing enzymes are able to participate in some consecutive elongation steps [99]. Suberin-related KCSs have been characterized in Arabidopsis and potato. AtKCS2/DAISY was first described by Franke et al. [70] as a salt stress-inducible docosanoic acid synthase, since daisy mutants produced root suberin that exhibited a concomitant decrease in C22 and C24 VLCFA-based constituent accumulation, with increased C16, C18, and C20 amounts. AtKCS20 was shown to be functionally redundant with AtKCS2, based 
on similar observations of C22 and C24 reductions in kcs20 mutants, and a more substantial alteration to root suberin aliphatics in $k c s 2 k \operatorname{cs} 20$ double mutants [12]. In potato, StKCS6 is involved in aliphatic suberin and wax monomer synthesis [10]. StKCS6 silencing led to a drop in C28 and greater chain lengths, and led to accumulation of C26 and shorter chains, indicating that StKCS6 acts on C26 substrates, but might elongate shorter chains as well.

The KCS-generated $\beta$-ketoacyl-CoA is reduced by a $\beta$-ketoacyl-CoA reductase to a hydroxyacyl-CoA. Beaudoin et al. [71] described a $\beta$-ketoacyl-CoA reductase (AtKCR1) that encodes an enzyme catalyzing the first reduction step by the fatty acid elongase complex to yield chain lengths greater than C18 for incorporation into different aliphatic polymers including the SPAD. There have been no potato homologs characterized to date.

The next step involves a 3-hydroxyacyl-CoA dehydrogenase-mediated dehydration of 3-hydroxyacyl-CoA to yield trans-2,3-enoyl-CoA. In Arabidopsis, AtPASTICCINO2 (At$P A S 2)$ encodes the third elongase complex enzyme [72]. While suberin-specific aliphatic analysis was not performed in AtPAS2 characterization, it has demonstrated involvement in synthesizing VLCFA used as precursors for various lipidic compounds, including seed storage triacylglycerols, cuticular waxes, and sphingolipids.

The final enzyme in the fatty acid elongase complex is an enoyl CoA reductase (ECR) that reduces its substrate into the elongated chain with two additional carbons. A gene has been characterized only in Arabidopsis, based on cer10 mutants. AtECR was characterized by Zheng et al. [73] and shown to be required for proper production of cuticular wax, seed triacylglycerols, and sphingolipid production; however, no suberin aliphatics were specifically analyzed.

\subsubsection{Oxidation}

Oxidation reactions yield modified fatty acids that comprise over half of the SPAD constituents in many plant species, including mid-chain epoxide and hydroxylated octadecanoates, and $\omega$-hydroxyalkanoic acids and their further oxidized $\alpha, \omega$-dioic acid derivatives generated from saturated 16:0 to 24:0 chains as well as 18:1 unsaturated fatty acid. The presence of hydroxylated and dioic VLCFAs suggests that higher chain length products undergo elongation prior to oxidation $[4,75]$. In potato suberin, $\omega$-hydroxy acids and dicarboxylic acids are predominant and together constitute ca. $65 \%$ of the SPAD, with negligible quantities of mid-chain modified fatty acids. In other species, for example cork oak, mid-chain epoxides, and hydroxyalkanoic acids, together comprise $>70 \%$ of the SPAD [41], while in Arabidopsis, root aliphatic suberin is made up of almost $70 \%$ $\omega$-hydroxy acids and dioic acids [100].

Terminal carbon hydroxylations are carried out by cytochrome P450 enzymes belonging to the 86A, 86B, 94A, and 704B subfamilies [101], of which many have been characterized in Arabidopsis and potato. An Arabidopsis CYP86A1 was first enzymatically characterized as a fatty acid $\omega$-hydroxylase by Benveniste et al. [74]. Studies of loss-of-function Atcyp86a1/horst and Atcyp86b1/ralph mutants demonstrated the role of two monooxygenases with varying substrate specificities and functions, where the former yields shorter-chain $\omega$-hydroxy acids $(\leq \mathrm{C} 18)$ and the latter is responsible for the formation of very-long-chain C22-C24 $\omega$-hydroxylated fatty acids in root and seed suberin $[15,16]$. The AtCYP86A1 ortholog in potato, StCYP86A33, has been characterized in forward and reverse genetics studies, where its silencing led to a reduction in 18:1 and 20:0 $\omega$-hydroxy acids and $\alpha, \omega$-dioic acids in tuber skin and a concomitant increase in 22:0 and 24:0 monomers [13]. StCYP86A33 expression was found to complement the Arabidopsis cyp86a1/horst-1 mutant by re-establishing production of oxidized monomers [14]. Complementation of horst-1 mutants with either AtCYP86A1 or StCYP86A33 resulted in an increase in longer-chain distribution than the typically most abundant hydroxylated and dioic 18:1 monomers that is not consistent with RNAi-induced observations [13,14]. This suggests these CYP86As could also use longer chains in addition to their demonstrated shorter-chain (C12-C18) substrates, or this result could be a byproduct of the experimental system $[13,14,74]$. 
Oxidation of $\omega$-hydroxyhexadecanoic acid, into its corresponding $\alpha, \omega$-dioic acid, was shown to be carried out by two NADP-dependent oxidoreductases in potato [75,77], though the genes have not been identified. In the sequence of reactions, an $\omega$-hydroxy fatty acid dehydrogenase first oxidizes the $\omega$-carbon of $\omega$-hydroxy fatty acids to produce an $\omega$-oxo fatty acid, which is further oxidized to a dicarboxylic acid by an $\omega$-oxo acid dehydrogenase $[75,76]$. Only the former appeared to be wound-induced in potato tubers, while the latter demonstrated higher activity than the first enzyme, despite a lack of wound-induced change, suggesting that the rate-limiting step for dicarboxylic acid production is the conversion of $\omega$-hydroxy to $\omega$-oxo acid [75]. Since longer-chain $\alpha, \omega$-dioic acids are present in the SPAD, this suggested pair of enzymes either may not have such a narrow chain length substrate specificity, or there may be other unidentified enzymes responsible for catalyzing these steps with longer chains. Studies in other species suggest that these enzymatic activities are carried out successively by a single monooxygenase. That is, the CYP94 family of monooxygenases have been implicated in catalyzing the formation of cutin and suberin $\omega$-hydroxy fatty acids and dioic acid monomers, by catalyzing $\omega$-hydroxylation of fatty acids. Some enzymes have additionally demonstrated a role in subsequent dicarboxylic acid formation. In vetch, the phytohormone-responsive VsCYP94A1 oxidizes the terminal methyl of C10-C16, C18:1, C18:2, and C18:3 fatty acids [102,103]. Tobacco NtCYP94A5 can oxidize the terminal methyl group of saturated and unsaturated C12-C18 fatty acids into $\omega$-hydroxy fatty acids, except for the C18:0 stearic acid, and the recombinant protein appears to act on 9,10-epoxystearic acid with the highest efficiency. NtCYP94A5 was the first plant enzyme observed to further catalyze the successive oxidation of its preferred substrate into its alcohol, aldehyde and $\alpha, \omega$-diacid counterparts [78]. The Arabidopsis AtCYP94C1 is a wound-responsive enzyme that can hydroxylate saturated, unsaturated and C12-C18 fatty acids, including epoxy-fatty acids. AtCYP94C1 activity exhibited a preference for $\mathrm{C} 12$ and $\mathrm{C} 18$ chains as substrates, with epoxystearic acid used most predominantly. Heterologous yeast microsome expression experiments demonstrated the ability of AtCYP94A1 to hydroxylate $\omega$-methyl groups and in-chain positions, and to additionally catalyze $\alpha, \omega$-dioic acid formation [79]. While no CYP94s have been characterized to date in potato, Bjelica et al. [14] demonstrated that the gene encoding a putative potato homolog of NtCYP94A5, StCYP94A26, is expressed in roots and wounded tubers.

\subsubsection{Reduction}

Fatty acyl-CoA reductases (FARs) catalyze the conversion of fatty acids to primary alkanols for incorporation in the SPAD. Domergue et al. [18] used loss-of-function mutant lines to describe the role of three suberin-related FARs in Arabidopsis; AtFAR1, AtFAR4, and AtFAR5. All are involved in primary alcohol biosynthesis in root suberin and appear to have different saturated chain length substrate specificities. In far1 mutants, C22 alcohols were reduced in quantity, far 4 mutants showed decreased C20 fatty alcohols and far 5 accumulated lower amounts of C18 alkanols, while heterologous expression in yeast demonstrated a range of chain length specificities from C18-C24 [18]. These fatty alcohol-forming enzymes also contribute toward formation of a large proportion of Arabidopsis root wax alkyl hydroxycinnamates $[19,104]$.

Acyl-activated VLCFAs can also be routed towards the synthesis of waxes that make up a soluble (i.e., unpolymerized) portion of the SPAD [105]. Decarboxylation reduces acylCoAs into intermediate aldehydes, and subsequent decarbonylation produces VLC-alkanes. In Arabidopsis, AtCER1 and AtCER3 encode core components of a redox-dependent multienzyme complex that interacts with electron-transferring cytochrome $b_{5}$ hemoproteins $\left(\mathrm{CYTB}_{5} \mathrm{~s}\right)$ as cofactors to perform these alkane forming reactions after activation by longchain acyl CoA synthase, AtLACS1 [2,80].

\subsection{Esterification, Deposition and Assembly of the Suberin Poly(aliphatic) Domain}

The SPAD contains modified fatty acid monomers linked to glycerol, and wax components such as alkyl ferulates that represent the convergence of the main suberin-associated 
phenolic and aliphatic monomer biosynthetic pathways. Aliphatic monomers such as $\omega-$ hydroxy acids and $\alpha, \omega$-dioic acids are linked together by esterification to glycerol $[46,49]$. The hydrophobic nature of aliphatic suberin constituents requires energetic export of these monomers from the plasma membrane into the lipophobic cell wall. Several plasma membranelocalized ATP-binding cassette (ABC) transporters have been associated with suberin assembly, e.g., $[25,26]$. This is an aspect of suberin assembly that remains poorly described.

\subsubsection{Acyl-CoA Dependent Aliphatic Monomer Esterification}

Glycerol 3-phosphate acyltransferases (GPATs) catalyze the transfer of acyl-CoAs to glycerol, to yield monoacylglycerols. GPATs exhibit different regiospecificity, where GPATs capable of catalyzing acylation of the $s n$-2 position of glycerol-3-phosphate represent a land plant-specific lineage of these enzymes [81]. Arabidopsis gpat5 loss-of-function mutants demonstrate substantial decreases in C20-C24 VLCFA and their $\omega$-hydroxy and dicarboxylic acid derivatives in suberin found in roots and seed coats, and overexpression of AtGPAT5 led to accumulation of sn-2 monoacylglycerols in the wax of Arabidopsis stems $[20,21]$. These findings support a sequence of biosynthetic events in which monooxygenase-mediated oxidation of a fatty acyl-CoA occurs prior to its linkage with glycerol [20,81]. The wound-inducible AtGPAT7 is in the same clade as AtGPAT5, and its overexpression resulted in the accumulation of suberin monomers [81].

Feruloyl-CoA transferases are involved in the conjugation of ferulic acid with modified fatty acid suberin monomers. Feruloyl transferases have been characterized in Arabidopsis and potato, where feruloyl-CoA acts as an acyl donor in the reaction with an $\omega$-hydroxy fatty acid acceptor to yield ferulate esters. The ferulate esters represent a point of convergence between the two major suberin-related biosynthetic pathways and also may act as a point of connection between suberin domains (see below), as they are proposed to promote linkage of the SPPD and SPAD, as well as between the SPPD and cell wall polysaccharides [5,106-108].

In potato periderm, feruloyl transferase StFHT is a wound-inducible gene encoding a fatty alcohol/fatty $\omega$-hydroxyacid hydroycinnamoyl acyltransferase that catalyzes the conjugation of ferulate to $\omega$-hydroxyacids and primary alcohols in suberin, and primary alcohols in associated wax. StFHT may have a role in the synthesis of $\omega$-feruloyloxy fatty acids that serve as precursors for $\omega$-feruloyloxy fatty acid glycerol esters [23,24]. In Arabidopsis, aliphatic suberin feruloyl transferase/ $\omega$-hydroxyacid hydroxycinnamoyltransferase (AtASFT/HHT) transfers feruloyl-CoA to $\omega$-hydroxy acids with an in vitro preference for 16-hydroxypalmitic acid and also demonstrates transferase activity toward primary fatty alcohols $[17,22]$.

\subsubsection{ATP-Binding Cassette (ABC) Transporters}

The transfer of suberin monomers, especially aliphatic monomers destined for the SPAD, are reliant in part on half-size ABC transporters and lipid transfer proteins [109]. For example, a rice transporter, RCN1/OsABCG5, is required for root suberization [84], while a pathogen-inducible potato transporter, StABCG1, is involved in the deposition of suberin in tuber skin [25]. RNAi-mediated silencing of StABCG1 led to the reduction of two major C18:1 aliphatic monomers, $\omega$-hydroxy-octadec-9-eneoic acid and its corresponding $\alpha, \omega$-dioic acid along with longer $(\geq C 24)$ chain $\omega$-hydroxy acids, dicarboxylic acids and fatty alcohols. Less ferulic acid was released in de-polymerized non-polar extracts than in control plants, while feruloyloxy fatty acids and their glycerol esters, and other ferulic acid conjugates had accumulated in the soluble fraction of apolar extracts. These observations indicate that StABCG1 exports major aliphatic monomers including those conjugated to ferulic acid and/or glycerol. More recently, the Arabidopsis homolog of StABCG1, AtABCG1, was shown to contribute to suberin formation in Arabidopsis roots [82]. AtABCG1 was stimulated by its substrates-up to $90 \%$ by fatty alcohols and acids with chain length C26C30 and C24-30, respectively. More importantly, several half-transporters were found to be involved, albeit each with different substrate specificity. StABCG11/WBC11 is the putative 
potato homolog of an Arabidopsis cuticle lipid exporter, AtABCG11/WBC11 [110]. While StABCG11/WBC11 has not been functionally characterized in potato, its root and tuberlocalized expression was shown to be regulated by the suberin-associated transcription factor StNAC103 [83]. Similarly, a putative ABC subfamily G, subgroup WBC/WHITE transporter is highly expressed in suberizing cork oak tissue [7].

Yadav et al. [26] used single, double, and triple $a b c g 2, a b c g 6$, and $a b c g 20$ loss-of-function mutant Arabidopsis lines to determine the role of these root and seed coat localized ABCG transporters. Aliphatic composition analysis of single mutants highlighted a role for each transporter in suberin production, although they did not have noticeable phenotypic changes. Triple mutants produced suberin with low levels of C20 and C22 saturated fatty acids, C22 alkanol, and C18:1 $\omega$-hydroxy acid and also displayed altered suberin organization and higher water permeability properties in roots and seed coats. The deposition of a suberin polymer in triple mutants, albeit altered, suggests that additional transporters are involved, and highlights the likeliness of substrate specificity along with some redundancy across transporters [26]. Lipid transfer proteins (LTPs) may be a possible supplementary mechanism of suberin monomer export, and while none have been directly linked to suberin deposition, several LTP-encoding genes were upregulated along with known suberin biosynthetic genes and ABCG transporters in an overexpression system studying a transcriptional regulator of suberization [111].

The ABCG transporter required for root suberization in rice, RCN1/OsABCG5, was identified from loss-of-function reduced culm number 1 (rcn1) mutant plants [84]. Relative to wild-type plants, lower quantities of C28 and C30 fatty acids, C16, C28, and C30 $\omega$ hydroxy fatty acids and C16 and C18 dioic acids with a concomitant increase in C24 and C26 $\omega$-hydroxy acids, are found in $\operatorname{rcn} 1$ mutant plants.

\subsubsection{Possible Mechanisms for Aliphatic Monomer Polymerization}

To date, no definitive mechanism(s) has been described with respect to the assembly of SPAD monomers into a polyester macromolecule. In potato periderm suberin, two key acylglycerol building blocks provide the basis of the SPAD: glycerol- $\alpha, \omega$-diacid-glycerol as the core block, and glycerol- $\omega$-hydroxy acid-ferulic acid to link the SPAD to the SPPD, see [29]. Given the similarity of aliphatic suberin and cutin, it is possible that SPAD monomers undergo an assembly process analogous to that of cutin. Cutin monomers include C16 and C18 $\omega$-hydroxylated acids, mid-chains with epoxy and hydroxyl groups. Primary functional groups can be linked to glycerol at different positions to form 1- and 2-monoacylgylceryl esters [112].

GDSL-lipase/hydrolase family cutin synthases are acyltransferases that mediate the transesterification of major cutin monomers esterified to glycerol. Cutin synthases from tomato fruit (S1CD1/S1CUS1) and Arabidopsis flowers (AtLTL1/AtCUS1) were shown to catalyze a two-step enzymatic polymerization reaction in vitro using a predominant cutin monomer as substrate [113-119]. First, cutin synthases act on a 2-mono(10,16-dihydroxyhexadecanoyl)glycerol molecule to generate an acyl-enzyme intermediate while freeing the glycerol moiety, then the intermediate reacts with another cutin monomer to yield a dimer. The polymerization reaction proceeds with fatty acyl groups from more molecules of the same monomer and increasingly larger oligomers as substrates $[113,116,118]$. However, tomato cutin synthase SICD1/SICUS1 produces only linear products from their acylglycerol substrates [115], and suppression of SlCD1/SlCUS1 expression in RNAi knockdowns and mutants led to a change in esterification of $s n-1,3$ and $s n-2$ positions of glycerol, demonstrating that SICD1/SICUS1 acts on primary and secondary hydroxyl groups of its cutin monomer substrates [116]. Together, these findings suggest that additional mechanisms are involved in cutin polymerization, including those responsible for branching and cross-linking of the polymer $[115,116]$. Due to the compositional similarities between the cutin and suberin polymers, it is feasible that GDSL-esterase/lipase enzymes may be involved in aliphatic suberin assembly, i.e., act as "suberin synthase" proteins analogous to cutin synthases [85]. While there is some overlap between cutin and 
aliphatic suberin monomers, there are several distinct monomers in each polymer, and therefore such enzymes would require the ability to use suberin-specific acylglycerols as substrates. More recently, the spontaneous self-assembly of covalently linked acyl-glycerolhydroxycinnamic acid trimers in extracts of potato periderm have been described [120]. These model building blocks of aliphatic suberin formed lamellar-like structures, and open the possibility of a non-enzymatic contribution to the overall structure of the polymer.

\subsection{The Temporal Deposition of Suberin: Predictions from the Potato Wound Healing Model}

Both metabolic [35] and gene expression [36,37] data demonstrate a temporal difference in phenolic and aliphatic metabolism during induced suberization in potato tubers. Using gene expression and chemical analysis data from wound-healing potato tubers, as a guide, the temporal deposition of the phenolic and aliphatic monomers of suberin is predicted to begin with the transport and polymerization of phenolics in the cell wall, followed by aliphatics in the space between the cell wall and plasma membrane (Figure 3 ). Accordingly, within $24 \mathrm{~h}$ post-wounding (hpw), phenolics would begin to accumulate in the cell wall and become cross-linked via a peroxidase-mediated process. The early deposition of phenolics is supported by release of phenolics by thioglycolic acid analysis and monolignols by derivatization followed by reductive cleavage (DFRC) analysis from extractive-free cell walls of wound-induced tubers undergoing suberization [70]. By contrast, it is not until between 48 and $72 \mathrm{hpw}$ that aliphatic suberin monomers/substructures begin to accumulate under the same conditions [119]. A critical step in the overall deposition of suberin, therefore, occurs at the transition between phenolic and aliphatic monomer deposition, since once the aliphatics are in place, their hydrophobic nature would reduce the feasibility of further transport of phenolics into the cell wall. Furthermore, the process cross-linking aliphatics to phenolics remains unclear. One possible mechanism to account for both the transition between phenolic and aliphatic monomer deposition and their cross-linking involves acyl-hydroxycinnamate esters that become cross-linked to the poly(phenolic) matrix. While speculative, this mechanism is supported by the expression of hydroxycinnamoyl transferases such as StFHT at this critical time post wounding [37]. Once the phenolicaliphatic transition is complete, additional aliphatic suberin monomers/substructures would be delivered to the surface of the cell wall where they become cross-linked to aliphatics (Figure 3).

The temporal deposition of suberin in wound-induced potato tubers may serve as a general model for suberin deposition in plant tissue. However, the coordinated deposition of phenolic and aliphatic monomers raises several questions, including how the process is regulated. There is also a limited amount of information about the poly(phenolic) composition of suberin polymers from species other than potato. 


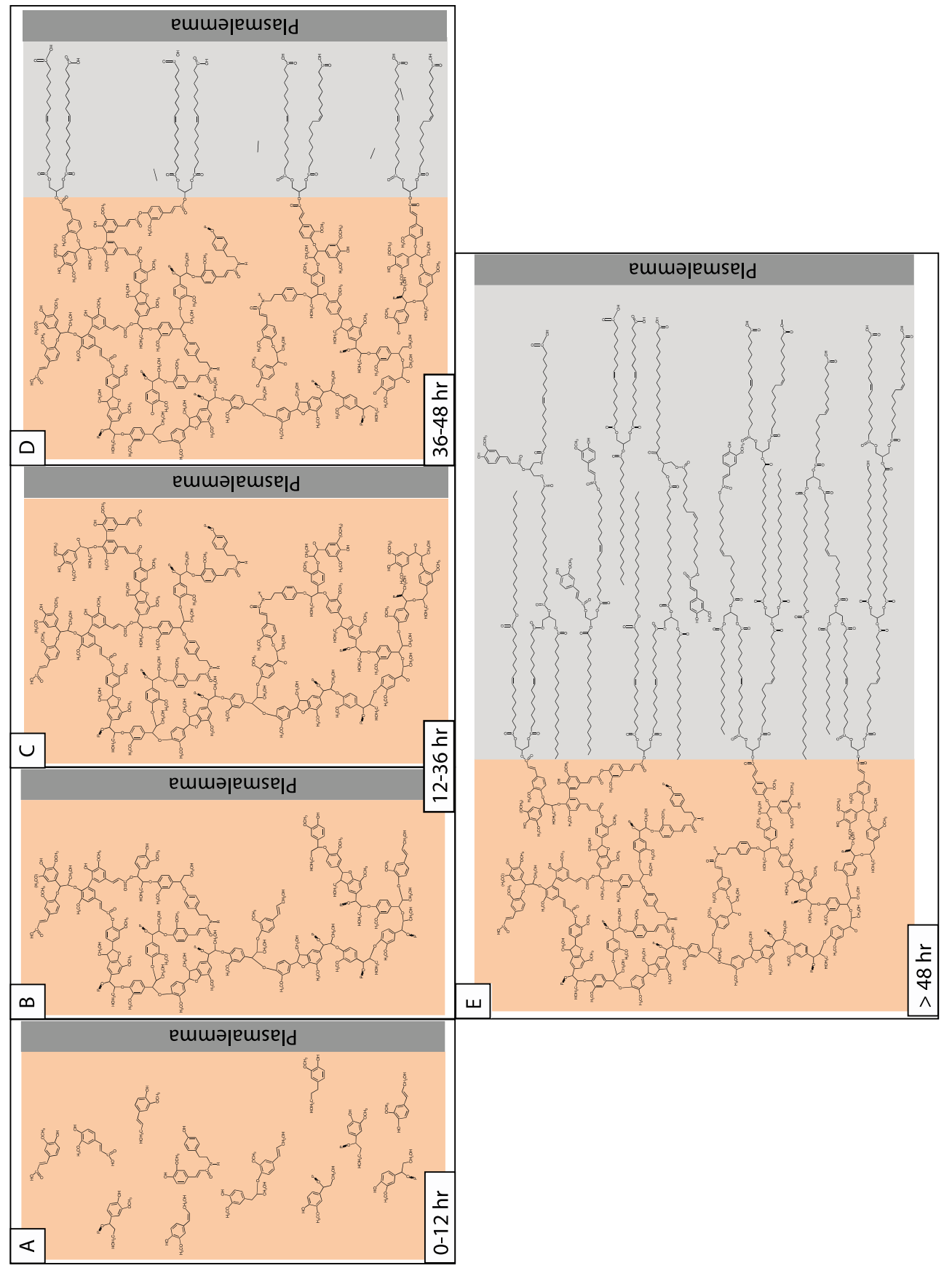

Figure 3. Time course of potato tuber wound suberin assembly. Using gene expression and chemical analysis data form wound healing potato tubers, the temporal deposition of the phenolic and aliphatic monomers of suberin is predicted to begin with phenolics in the cell wall (arrange), followed by aliphatics in the space (grey) between the cell wall and plasmalemma. (A) Within $12 \mathrm{hpw}$, phenolics begin to accumulate in the cell wall and become cross-linked via a peroxidase-mediated process. (B,C) Between 12-36 hpw, phenolics continue to accumulate and become cross-linked within the cell wall. (D) Approx. 36-48 hpw, acyl-hydroxycinnamate esters become cross-linked to the poly(phenolic) matrix, forming a transition between phenolic and aliphatic suberin deposition. (E) After $48 \mathrm{hpw}$, aliphatic suberin monomers/substructures are delivered to the surface of the cell wall where they are cross-linked to aliphatics at the surface of the cell wall. 


\section{Regulation of Suberization}

The differential timing of SPPD and SPAD monomer synthesis and deposition suggests that the enzymes involved in these biosynthetic pathways are controlled by different modes of regulation. The mechanistic details of this differential regulation are not understood, but some aspects of the regulation of suberin biosynthesis have been described (Figure 4). For example, a role for the phytohormone abscisic acid (ABA) has long been implicated as a regulator of suberization, including at the level of gene expression. More recently, transcription factors from different plant species have been demonstrated to control suberin biosynthetic gene expression, and Casparian strip membrane domain proteins (CASPs) have been implicated in the precise cellular deposition of suberin monomers, but especially phenolics.

Phytohormones are involved in complex signaling networks to control physiological events, including the regulation of normal growth and development, and the coordination of abiotic and biotic stress responses. Accordingly, several phytohormones are known to mediate wound-induced signaling and gene expression, e.g., [121]. In the case of suberization, the putative roles of abscisic acid (ABA) $[14,24,36,122,123]$, salicylic acid (SA) [24], jasmonic acid (JA) [122,123], and ethylene [124] have been investigated. However, to date, only ABA has been shown to have a definitive role.

\subsection{Phytohormone Regulation of Suberization}

\subsubsection{Abscisic Acid}

Abscisic acid is a carotenoid-derived signaling molecule involved in many developmental and stress-related processes in plants, including responses to drought and plantpathogen interactions $[125,126]$. Abscisic acid has long been considered to play a regulatory role in potato tuber suberization. Given the established role of ABA in drought and pathogen stress responses, the involvement of $\mathrm{ABA}$ in suberization is consistent with the physiological function of suberin in the protection against water loss and infection.

Soliday et al. [127] first posited the likely role of ABA in wound-induced tuber suberization after observing that ABA was released into a solution used to wash cut potatoes. Washing in the first two days after wounding was shown to prevent or delay suberization and the exogenous addition of ABA to washed tuber slices partially reversed this inhibition. Soliday et al. [127] proposed that in the early phase of wound-healing, ABA formation triggers some suberization-inducing factor that lead to the induction of enzymes for suberin biosynthesis. Follow-up work by Cottle and Kolattukudy [45] determined that suberin and its associated waxes increased with ABA treatment. A slight enhancement of $\omega$-hydroxy fatty acid dehydrogenase and phenylalanine ammonia-lyase activity, and a significant increase in suberization-associated peroxidase activity were observed after ABA treatment, linking ABA to the induction of suberization enzymes [45].

De novo ABA biosynthesis is triggered by wounding tubers as shown by an increase in $\mathrm{ABA}$ accumulation and the induction of $\mathrm{ABA}$ metabolism at the transcriptional level $[122,123,128,129]$. Lulai et al. [122] provided further evidence of a role for ABA in wound-induced suberin deposition using the ABA biosynthetic inhibitor fluridone (FD), which targets the phytoene desaturase enzyme involved in carotenoid biosynthesis [130], effectively diminishing substrate levels for de novo ABA production [122]. While the impact of FD on suberization was only described using a fluorescence microscopy-based qualitative rating system, the impact of $\mathrm{ABA}$ inhibition and exogenous $\mathrm{ABA}$ application both appeared to be stronger on the SPAD relative to the SPPD. Endogenous ABA accumulation also promotes potato microtuber dormancy [131], and ABA levels decrease with age in resting tubers. The latter is linked to an age-associated increase in water permeability and loss of wound-healing ability [128]. 


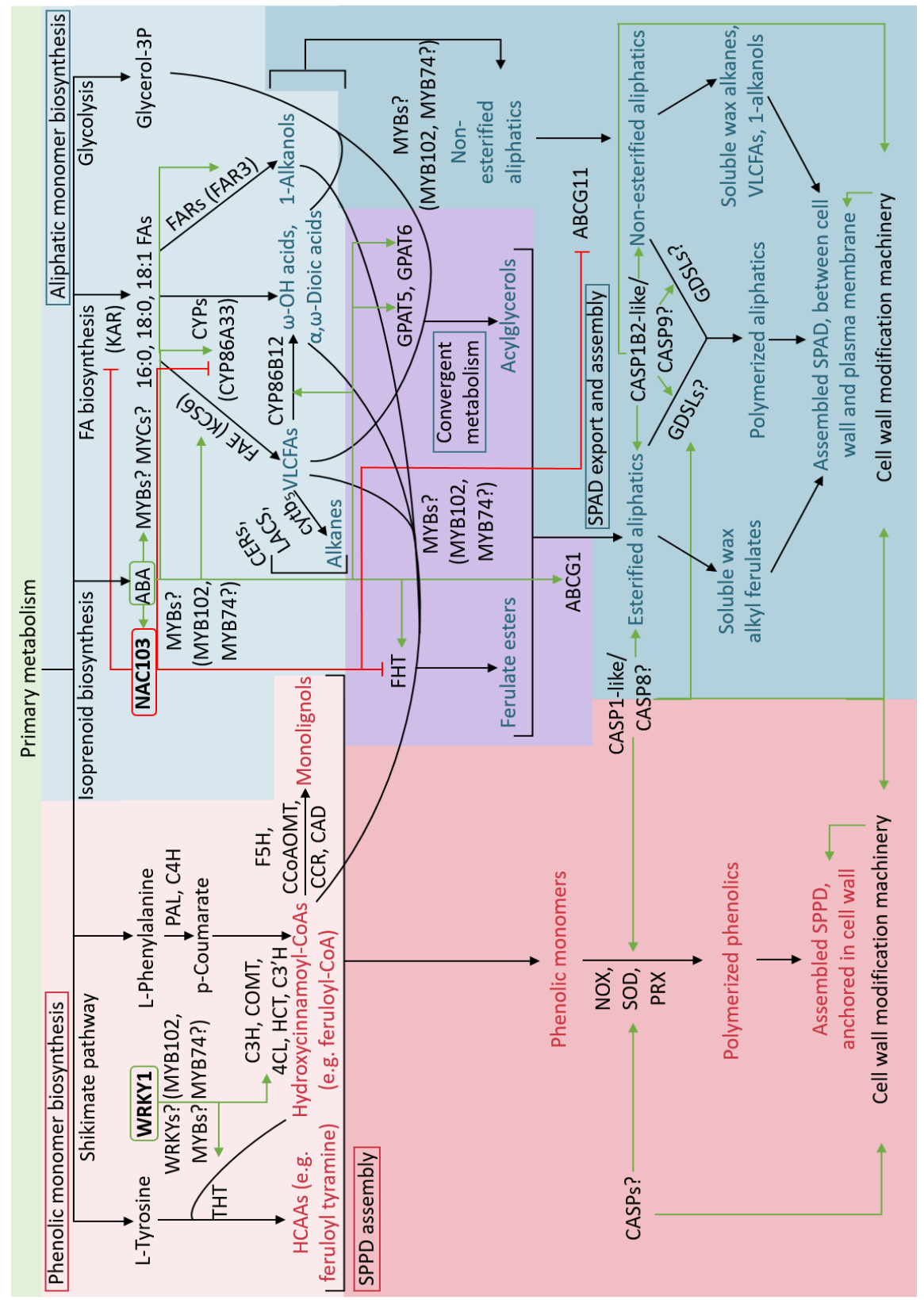

Figure 4. Overview of the regulation of suberin biosynthesis and assembly in wound-healing potato tubers. This overview offers a synthesis of findings, and proposes mechanisms of regulation at the levels of monomer biosynthesis, deposition, polymerization and assembly, based on the literature described in this review. Primary metabolic pathways (shaded green) yield precursors and energy molecules that feed into specialized suberin-related metabolic branches. For example, carbohydrate metabolism yields erythrose-4-phosphate and phospho-enol-pyruvate as precursors to the shikimate pathway and production of aromatic amino acids used as precursors for phenolic suberin biosynthesis. Pyruvate and glycolysis-derived glyceraldehyde-3-phosphate are used for the isoprenoid metabolism that yields the phytohormone abscisic acid (ABA) via the carotenoid pathway. Pyruvate is also a substrate for the tricarboxylic acid cycle that yields acetyl-CoA for fatty acid biosynthesis, and results in the generation of 16:0, 18:0 and 18:1 fatty acids that undergo various modifications for aliphatic suberin monomer production. Glycerol-3-phosphate is synthesized from the dehydrogenation of dihydroxyacetone phosphate produced during glycolysis. The biosynthesis of suberin poly(phenolic) domain monomers (dark red) may be regulated by WRKY and MYB TFs. WRKY1 regulates THT and 
$4 C L$ in relation to phenylpropanoid metabolism in pathogen-infected aerial potato organs. MYB74 and MYB102 may also regulate phenylpropanoid metabolism in potato tuber suberization. ABA regulates the biosynthesis of several key suberin poly(aliphatic) domain monomers (blue) by positively impacting genes involved in their production. NAC103 acts as a transcriptional suppressor of fatty acid and aliphatic suberin-related genes, and is induced by ABA. MYB TFs such as MYB102 and MYB74 may positively regulate aliphatic suberin production. (See Table 1 for key suberin biosynthetic genes and Table 2 for other TFs that regulate phenylpropanoid and/or fatty acid biosynthesis in other species.) It is feasible that potato orthologs of TFs characterized in other species may regulate suberization in wounded tubers. Most phenolic monomers are solely polymerized and incorporated into the SPPD. Feruloyl-CoA can also be conjugated to very long-chain fatty acids (VLCFAs), $\omega$-hydroxy and $\alpha, \omega$ dioic acids, and 1-alkanols to yield ferulate esters, including alkyl ferulates as SPAD-associated soluble wax components. Modified fatty acids can also be esterified to glycerol via the glycerol-3-phosphate acyltransferases (GPATs). Esterified aliphatic constituents are exported by ABCG1. These steps represent a point of convergence between the two major suberin biosynthetic pathways and are labeled as "convergent metabolism" (shaded purple) in the figure. MYB TFs such as MYB102 and MYB74 are putative regulators of the genes encoding convergent metabolic steps. The translocation of aliphatic monomers (alkanes, VLCFAs, modified fatty acids, 1-alkanols) that are not esterified to glycerol or feruloyl-CoA (i.e., soluble components destined for polymerization, or that remain non-polymerized as associated wax) has not been established in potato, but ABCG11 has predicted involvement. Phenolic monomers are thought to undergo a NADPH-dependent oxidase (NOX), superoxide dismutase (SOD), and anionic peroxidase (PRX)-mediated polymerization, whereas SPAD polymerization activities remain uncharacterized. CASP and GDSL-like proteins may play a role in SPAD polymerization. Phenolic suberin associated CASPs may recruit machinery such as NOX, SOD, PRX for polymerization, and influence enzymes involved in the organization of cell wall polysaccharides in a process that may be associated with SPPD deposition via localization of cell wall modifying activities. CASP1-like/CASP8 could regulate the linkage between two domains, their spatial organization, and/or the polymerization and deposition of esterified aliphatics that act as building blocks for SPAD assembly. CASP9 may coordinate aliphatic suberin assembly. GDSLs may act as "suberin synthases" at this stage of assembly, akin to cutin synthases. ABCG1 is required for the export of aliphatic suberin components. ABCG11 is suppressed by NAC103. ABCGs with varied substrate specificities and MYB TFs are likely involved in the export, deposition and polymerization of non-esterified aliphatics, as well as the organization of non-polymerized, soluble waxes. Cell wall modification machinery may be regulated by CASPs (e.g., CASP1B2-like/CASP9) to organize the deposition of polymerized aliphatics between the cell wall and plasma membrane, prior to secondary cell wall formation. $\mathrm{Ab}$ breviations: 4CL, 4-coumarate-CoA ligase; ABA, abscisic acid; ABCG1, ATP-binding cassette (ABC) subfamily G transporter 1; ABCG11, ATP-binding cassette (ABC) subfamily G transporter 11; ABCG6, ATP-binding cassette $(\mathrm{ABC})$ subfamily $\mathrm{G}$ transporter 6; $\mathrm{C} 3 \mathrm{H}$, p-coumarate 3-hydroxylase; $\mathrm{C}^{\prime} \mathrm{H}$, p-coumaroyl quinate/shikimate 3'-hydroxylase; $\mathrm{C} 4 \mathrm{H}$, cinnamic acid 4-hydroxylase; $\mathrm{CAD}$, cinnamyl alcohol dehydrogenase; CASP8, Casparian strip membrane domain protein 8; CASP9, Casparian strip membrane domain protein 9; CCoAOMT, caffeoyl-CoA O-methyltransferase; CCR, cinnamoyl CoA reductase; CER, ECERIFERUM; COMT, caffeic acid O-methyltransferase; CYP, cytochrome P450; CYP86A33, cytochrome P450 subfamily 86A 33; CYP86B12, cytochrome P450 subfamily 86B 12; $\mathrm{CYTB}_{5}$, cytochrome $b_{5} ; \mathrm{F5H}$, ferulate 5-hydroxylase; FA, fatty acid; FAE, fatty acid elongase; GDSL, GDSL domain esterase/lipase; Glycerol-3P, glycerol-3-phosphate; GPAT5, glycerol-3-phosphate acyltransferase 5; GPAT6, glycerol-3-phosphate acyltransferase 6; HCAA, hydroxycinnamic acid amide; HCT, hydroxycinnamate transferase; KAR, $\beta$-ketoacyl-ACP reductase; KCS6, $\beta$-ketoacylCoA reductase 6; LACS, long-chain acyl-CoA synthetase; MYB, MYB family transcription factor; NAC, NAC domain transcription factor (NAM, no apical meristem, ATAF, Arabidopsis transcription activation factor, and CUC, cup-shaped cotyledon); NOX, NADPH-dependent oxidase; PAL, phenylalanine ammonia lyase; PRX, anionic peroxidase; SOD, superoxide dismutase; SPAD, suberin poly(aliphatic) domain; SPPD, suberin poly(phenolic) domain; THT, tyramine hydroxycinnamoyl transferase; VLCFA, very-long-chain fatty acid; WRKY, WRKY domain family transcription factor. 
Several independent lines of evidence have established that de novo ABA biosynthesis is induced upon wounding and promotes the wound suberization processes via upregulation of suberin biosynthetic genes. For example, Woolfson et al. [36] used FD to investigate the role of $\mathrm{ABA}$ in the regulation of suberin by inhibiting de novo ABA biosynthesis, with and without the addition of exogenous ABA. Transcript accumulation of key aliphatic suberin-associated genes, including StCYP86A33, StCYP86B12, StFAR3, and StKCS6 was delayed post-wounding by FD treatment, whereas exogenous ABA application (with or without FD treatment) enhanced transcript accumulation of these same aliphatic suberin associated genes. Similarly, insoluble aliphatic monomer accumulation was reduced in FD-treated tissues. In contrast, FD treatment had no apparent impact on the transcript accumulation of phenolic metabolism genes, while exogenous ABA and the combined FD + ABA treatments slightly increased the accumulation of some polar metabolites [36]. While Kumar et al. [128] demonstrated that the application of exogenous ABA to woundinduced tubers enhanced PAL1 transcription during phenolic suberin biosynthesis, the overall impact on phenolic metabolism was less clear. Together, these findings suggest a role for ABA in the differential induction of phenolic and aliphatic metabolism during wound-induced suberization, at least in potato tubers [36]. In contrast, Han et al. [132] demonstrated that enzymes involved in polar metabolite synthesis, PAL, cinnamyl-alcohol dehydrogenase (CAD), and peroxidase (PRX), were induced by ABA in wounded kiwi (Actinidia deliciosa (Chev.) Liang and Ferguson) fruit tissue. Exogenous ABA application also led to increased content of phenols, flavonoids, alkanes, alkenes, alcohols, alkane acids, olefine acids, esters, glycerides, and tocopherols in wounded tissue. Han et al. [132] concluded that ABA stimulates suberin biosynthesis via activation of PAL, CAD, and POD to accelerate healing in wounded kiwifruit.

Overall, the involvement of ABA in wound-induced and native periderm suberization is evident, but knowledge of its targeted impact on recently characterized biosynthetic steps is limited. The identification of ABA-responsive promoter regions in suberin aliphatic biosynthetic genes, such as cytochrome P450s [14] and feruloyl transferase (StFHT; [24]) provide support for the direct control of these genes by ABA. In silico analysis of the putative promoter region of the key potato suberin aliphatic gene StCYP86A33 led to the identification of several ABA-linked response elements [14]. Regulation of fatty acid $\omega$-hydroxylation is essential during suberin biosynthesis, as more than $55 \%$ of aliphatic suberin monomers are oxidized prior to incorporation into the aliphatic suberin domain of the biopolymer [41,119]. The StFHT promoter region contains numerous putative hormoneand stress-responsive cis-regulatory motifs, including those associated with ABA, jasmonic acid (JA) and salicylic acid (SA) [24]. However, only exogenous ABA application led to the induction of StFHT expression in wound-healing tubers [24].

In Arabidopsis, ABA plays a central role in suberin biosynthesis and deposition in drought-induced stress in Agrobacterium-induced tumors [133]. Specifically, Agrobacteriuminduced tumors in Arabidopsis accumulated high amounts of ABA, the ethylene precursor aminocyclopropyl carboxylic acid, osmoprotectants, and formed a suberized peridermlike protective layer. Analysis of gene expression in tumor tissue pointed to a distinct mechanism of drought acclimation in Agrobacterium-induced tumors, which differs from that of other tissues, such as leaves or roots. Several suberin related genes regulated by drought and/or ABA showed transcriptional activation in tumors, such as fatty acid $\omega$-hydroxylase (AtCYP86A1), phenylalanine-ammonia lyase (AtPAL1) and 4-coumarateCoA ligase $(A t 4 C L 2)$ as well as a suberin-associated peroxidase and lipid-transfer protein (AtLTP2) [133].

Abscisic acid is also involved in the developmental deposition of Arabidopsis root suberin, and likely plays a role in the suberization response to nutrient availability [124]. Barberon et al. [124] established that in the root endodermis, suberization can be enhanced, or suberin can be selectively degraded, depending on the plant's nutritional status. This plasticity appears to be regulated by ABA (for suberin development) and ethylene (for reversal of suberization) [124]. Using a live marker for suberization, the glycerol-3-phosphate 
acyltransferase GPAT5 (a key suberin biosynthetic enzyme) [20] and GPAT5-driven GUS activity, Barberon et al. [124] demonstrated a match between the pattern of suberin deposition in Arabidopsis roots [40] and GPAT5 localization via the transcriptional reporter line GPAT5::mCITRINE-SYP122. Using this reporter system, it was shown that ABA rapidly induces suberization and led to ectopic deposition in young root parts, as well as in the cortex [124].

\subsubsection{Other Phytohormones}

Other phytohormones, such as jasmonic acid (JA) and ethylene [120,122], do not seem to be involved in wound-induced suberin biosynthesis in potato tuber, although Barberon et al. [124] provided evidence for ethylene interference during the process of the developmental deposition of Arabidopsis root suberin. That is, ethylene application to developing Arabidopsis roots resulted in apparent degradation of suberin in root endodermal cells [124]; however, aliphatic suberin was not quantitatively assessed. By contrast, inhibition of ethylene biosynthesis had no obvious effect on wound-induced suberin production in potato tubers $[123,134]$. Similarly, a role for JA in induced suberin biosynthesis remains ambiguous. For example, while the amount of JA increases upon tuber wounding, intracellular levels decline again as ABA and ethylene levels approach their maximum [123]. However, a role for JA in induced suberin biosynthesis cannot be completely ruled out since it has been implicated in the regulation of cell wall damage-induced lignin biosynthesis in Arabidopsis [135], and the suberin poly(phenolic) domain contains monomers in common with lignin. Moreover, as noted above, the suberin-associated gene StFHT contains many putative hormone-responsive motifs [24] including those associated with JA and salicylic (SA). However, tubers treated with JA demonstrated no change in, and SA application led to suppression of, StFHT expression [24].

\subsection{Transcription Factors}

Transcription factors (TFs) are proteins that bind to specific sequences of their target genes to control transcription, i.e., gene expression. Similar to the role of phytohormones, transcription factors are implicated in the regulation of plant growth and development and in various stress responses and can function within highly coordinated signaling pathways.

Fifty-eight families of TFs, comprising approximately 320,370 members, have been described in 165 plant species [136]. Several major TFs families have demonstrated involvement in biotic and abiotic stress responses $[137,138]$ including: myeloblastosis related (MYB), myelocytomatosis (MYC), NAC domain (NAM, ATAF, and CUC) proteins, WRKY domain proteins, APETALA2/ethylene responsive factor (AP2/ERF), basic helix-loop-helix (bHLH), and basic leucine zipper (bZIP).

In the context of secondary metabolism, TFs have been shown to regulate entire pathways including multiple branches (e.g., Vitis vinifera VvMYB5a that controls the phenylpropanoid pathway in grapevine) [139] or subgroups of pathway genes, and under stressspecific conditions (e.g., the wound-, pathogen-, and UV-inducible poplar PtMYB134 that controls the proanthocyanidin branch of phenylpropanoid biosynthesis) [140]. In the context of suberin deposition, MYB, MYC, NAC, and WRKY TFs from Arabidopsis, potato, kiwifruit, cork oak, and apple have been described (Table 2). 
Table 2. Transcription Factors involved in the regulation of suberin biosynthesis and deposition. Transcription factors are summarized according to type and listed in order based on numbering. Multiple entries for a given TF occur when the same TF is described in more than one species or tissue. Only the main tissues in which the TFs have been described are listed, and does not imply that they aren't functional in other tissues. Similarly, the main signals listed are in reference to the conditions in which a given TF was discovered or tested. Wounding is listed separately from the more generic "abiotic" signal since wounding is a common treatment to initiate suberization. Strictly speaking, no WRKY TFs have been directly shown to be involved in suberization; however, their induction by wounding, and the link between wounding and induced suberization warrant their inclusion.

\begin{tabular}{|c|c|c|c|c|c|c|c|}
\hline \multicolumn{2}{|c|}{ Transcription Factor } & \multirow[t]{2}{*}{ Plant Species } & \multirow[t]{2}{*}{ Tissue } & \multirow[t]{2}{*}{$\begin{array}{c}\text { Type of } \\
\text { Regulation }\end{array}$} & \multirow[t]{2}{*}{$\begin{array}{c}\text { Target } \\
\text { Pathway }{ }^{2}\end{array}$} & \multirow[t]{2}{*}{ Signal } & \multirow[t]{2}{*}{ Reference } \\
\hline Family & Name & & & & & & \\
\hline \multirow{11}{*}{ MYB } & MYB1 & Quercus suber & Cork & + & $\mathrm{P}$ & Abiotic & [141] \\
\hline & MYB4 & Actinidia deliciosa & Fruit & - & FA & $\mathrm{ABA}$ & [142] \\
\hline & MYB36 & Arabidopsis thaliana & Root & + & FA, $\mathrm{P}$ & Differentiation & [143] \\
\hline & MYB39 & Arabidopsis thaliana & Seed coat, root & + & $\mathrm{FA}, \mathrm{P}$ & Developmental & {$[85,144]$} \\
\hline & MYB41 & Arabidopsis thaliana & Root & + & $\mathrm{FA}, \mathrm{P}$ & ABA, abiotic & [38] \\
\hline & MYB41 & Actinidia deliciosa & Fruit & + & FA & ABA, developmental & [145] \\
\hline & MYB74 & Solanum tuberosum & Wound periderm & + & FA & Wounding & [146] \\
\hline & MYB93 & Malus $\times$ domestica & Fruit skin & + & FA & Developmental & [111] \\
\hline & MYB102 & Solanum tuberosum & Wound periderm & + & FA & Wounding & [146] \\
\hline & MYB107 & Arabidopsis thaliana & Seed coat & + & FA, $\mathrm{P}$ & Developmental & [85] \\
\hline & MYB107 & Actinidia deliciosa & Shoot, leaf & + & FA & $\mathrm{ABA}$ & [145] \\
\hline$\times \mathrm{MYC}$ & MYC2 & Actinidia deliciosa & Root, shoot, leaf & + & FA & $\mathrm{ABA}$ & [145] \\
\hline \multirow[t]{2}{*}{ NAC } & ANAC046 & Arabidopsis thaliana & $\begin{array}{l}\text { Root, floral bud, fruit, } \\
\text { leaf, wounded leaf }\end{array}$ & + & FA & $\begin{array}{l}\text { Wounding, } \\
\text { developmental, } \\
\text { senescence }\end{array}$ & [147] \\
\hline & NAC103 & Solanum tuberosum & $\begin{array}{l}\text { Wound periderm, } \\
\text { leaf, periderm, root }\end{array}$ & - & FA & $\begin{array}{l}\text { ABA, wounding, } \\
\text { developmental }\end{array}$ & [83] \\
\hline WRKY & WRKY1 & Solanum tuberosum & Stem & + & $P$ & Biotic/abiotic & [148] \\
\hline
\end{tabular}

$1+$ = positive; - = negative ${ }^{2} \mathrm{P}=$ phenylpropanoid; $\mathrm{FA}=$ fatty acid.

\subsubsection{MYB and MYC Transcription Factors}

Several transcription factors have been described as regulators of suberin biosynthesis and deposition and are also important components of ABA signaling in response to abiotic stresses in plants. For example, Kosma et al. [38] confirmed that the transcription factor AtMYB41 is a positive regulator of suberin biosynthesis and deposition under abiotic stress conditions. Overexpression of AtMYB41 in leaves of Nicotiana benthamiana resulted in the ectopic accumulation of transcripts for aliphatic suberin biosynthesis genes (e.g., AtCYP86A1) and related metabolites ( $\omega$-hydroxy fatty acid and dicarboxylic acids). Overexpression of $A t M Y B 41$ also led to increased phenylpropanoid and lignin biosynthetic gene transcripts and production of some metabolites like monolignols in leaves. Furthermore, the ectopic deposition of suberin in leaf epidermal and mesophyll cells resulting from overexpression of $A t M Y B 41$ resembled that typically observed in roots and native and wound potato tuber periderm [38]. Similarly, overexpression of AtMYB92 in N. benthamiana resulted in a significant increase in the accumulation of suberin-related aliphatics [149].

MdMYB93 was identified by Legay et al. [150] in russeted apples (Malus $\times$ domestica) with high suberin deposition in fruit skins, via comparative transcriptomic analysis with non-russeted varieties. The authors demonstrated a correlation between MdMYB93 expression and putative apple homologs of AtCYP86A1, AtGPAT5, and AtCYP86B [150]. Subsequently, Legay et al. [111] used a heterologous $N$. benthamiana expression system to transiently overexpress $M d M Y B 93$ and measure its impacts on suberin related metabolism and transcriptome-wide gene expression. MdMYB93 expression in agroinfiltrated N. benthamiana leaves was accompanied by increased accumulation of suberin biosynthetic gene transcripts including those involved in cell wall development, lipid, and phenylpropanoid metabolism and ABCG family transporters. Overexpression of MdMYB93 also changed the composition of phenolic metabolites in N. benthamiana leaves [111], though their potential role in SPPD formation was not investigated. 
Transcriptomic studies of suberization in wounded cuticle-deficient tomato (Solanum lycopersicum) and russeted apple (Malus $\times$ domestica) fruit skins demonstrated the upregulation of suberin-related genes in suberized skin tissues [85]. Comparative transcriptome co-expression analyses using additional plant species and tissues revealed a conserved gene expression signature of 26 genes for suberin monomer synthesis and polymer assembly among angiosperms. Co-expression analyses led to the identification of putative orthologs in a suberin-linked MYB clade, including tomato SIMYB93, apple MdMYB53, grape VvMYB107, potato StMYB93, rice OsMYB93, and Arabidopsis AtMYB107 and At$M Y B 9$ [85]. Lashbrooke et al. [85] confirmed the role of AtMYB107 and AtMYB9 in suberin biosynthesis and assembly through the analysis of loss-of-function mutants, in which they observed a significant reduction in suberin phenolic and aliphatic monomer components. The authors concluded that AtMYB9 and AtMYB107 coordinate the transcriptional regulation of phenolic and aliphatic monomer biosynthesis and deposition in suberizing tissue.

A combination of targeted metabolomics and transcript profiling in wounded tubers, and heterologous expression in N. benthamiana led to the identification and initial characterization of two additional potato TFs, StMYB102 and StMYB74, that regulate wound suberization processes $[85,146]$. The accumulation of significant amounts of aliphatic suberin monomers in leaves of $N$. benthamiana expressing either StMYB102 or StMYB74 supports a role for these two TFs in the regulation of aliphatic suberin deposition. Since phenolic deposition is required for normal suberin lamella deposition [39], and heterologous expression of StMYB102 and StMYB74 in N. benthamiana leaves resulted in the deposition of suberin lamellae between the plasma membrane and cell wall, StMYB102 and StMYB74 are also implicated in the regulation of suberin phenolic deposition. Differential expression of StMYB102 and StMYB74, and single nucleotide polymorphisms in StMYB102, all correlate with the amount of wound-suberin deposited by different cultivars [146]. These data provide important insight into the basis of quantitative differences in the amount of suberin deposited in different potato cultivars.

Cohen et al. [144] described SUBERMAN (SUB), a MYB-type transcription factor (i.e., AtMYB39) associated with the deposition of suberin monomers in the root endodermis layer that acts as a positive regulator of suberin deposition during normal development. Transient expression of AtMYB39 in N. benthamiana leaves resulted in the induction of heterologous suberin genes, the accumulation of major suberin monomers, and the deposition of suberinlike lamellae. Indeed, SUB activated the promoters of genes involved in suberin deposition and therefore could control the expression of suberin biosynthesis genes. Analysis of gene expression profiles provided insight into the influence of $S U B$ on root endodermis suberization during natural development. Generally, SUB affects transcriptional networks linked with suberin deposition, including the biosynthesis of phenylpropanoids, lignin (i.e., poly(phenolic) domain), very-long-chain-fatty-acid (VLCFA)-CoA, cuticular lipid components, root transport activities, hormone signaling, and cell wall regulation. SUB regulation of suberin biosynthesis and deposition appears to be specific to root endodermis, but does not affect CS formation [144]. The latter point supports the notion that CS formation and suberin lamellae deposition are distinct processes [124], but does not rule out a role for both phenolic and aliphatic monomer deposition in CS, as measured for maize [151] and soybean [152].

QsMYB1 is a MYB family member described from cork oak (Quercus suber) and shown to be involved in the regulation of phenylpropanoid and lignin pathways expressed in organs and tissues that undergo secondary growth [141]. QsMYB1 expression is moderated by an alternative splicing mechanism that results in two different transcripts: QsMYB1.1 and QsMYB1.2. Each transcript was differentially expressed, depending on the nature of the abiotic stress applied to the tissue. For example, accumulation of QsMYB1.1 transcripts were downregulated slowly at high temperatures, while QsMYB1.2 was temporarily upregulated in response to drought stress [153]. Capote et al. [154] developed a ChIP-Seq strategy for analysis of the DNA targets of QsMYB1 across the cork oak genome, and determined that several genes were targeted by QsMYB1, including those encoding enzymes for monolignol 
and phenolic suberin component biosynthesis. Additionally, several members of the ABCG gene family and lipid-transfer proteins (LTPs) were regulated by QsMYB1, which signifies the important role of QsMYB1 in the regulation of lipid transport and suberin formation across the cellular membrane [154].

In kiwifruit, five TFs, AchnMYC2, AchnMYB4, AchnMYB41, AchnMYB107, and AchnABF2, which regulate expression of AchnCYP86A1 [142,145], AchnFHT [155], and AchnFAR [142,156] have been identified. More specifically, AchnMYC2, AchnMYB41, and AchnMYB107 individually interacted with the AchnCYP86A1 promoter to activate gene expression [145], and heterologous expression in $N$. benthamiana resulted in the accumulation of $\omega$-hydroxy acids, $\alpha, \omega$-diacids, fatty acids and primary alcohols. The increase in primary alcohols was later shown to correlate with increased AchnFAR expression [156]. Similarly, yeast 1-hybrid and dual-luciferase analyses demonstrated that AchnABF2, AchnMYB41, and AchnMYB107 activated the AchnFHT promoter, while AchnMYB4 acted as a repressor [155]. The authors concluded that the activation of suberin assembly, involving AchnFHT, was fine-tuned through both repression by AchnMYB4 and promotion by AchnABF2, AchnMYB41, and AchnMYB107.

\subsubsection{NAC Transcription Factors}

The NAC family constitutes one of the largest transcription factor families in land plants and is represented by 110 genes in potato [157]. NAC transcription factors are involved in various plant functions from development, lateral root formation and auxin signaling [158] to secondary cell wall biosynthesis [159], and stress response regulation [160]. In potato, a large proportion of NAC genes are sensitive to abiotic stresses [83,161]. StNAC103 was recently described by Verdaguer et al. [83] as a wound- and ABA-inducible negative regulator of aliphatic suberin and wax accumulation. Its promoter drove GUS expression in native and wound periderm phellem cells undergoing suberization, and also in tissues that do not produce suberin, namely lateral root primordia and root apical meristems. Its RNAi-mediated gene silencing led to the significant upregulation of genes with predicted or known involvement in different branches of suberin-related metabolism: StCYP86A33, StKAR, StFHT, and StABCG11/StWBC11. Although TF binding activities were not investigated, the impact of StNAC103-silencing on these genes was consistent with an increase in their substrates, such as alkylferulate wax components, $\omega$-hydroxy acids, primary alcohols, and alkanes. The observed transcriptional repression activities of StNAC103 likely control suberin synthesis during wound-healing on a fine scale, and probably function to prevent premature suberization in certain root localizations in vivo [83]. In Arabidopsis, AtANAC046 facilitates the deposition of suberin in roots, particularly in the endodermis of primary roots and the periderm of secondary roots, and in leaves in response to wounding [147]. A comparison between overexpression (OE) and wild-type (WT) lines indicated that the expression of suberin biosynthesis genes was higher in the roots and leaves of OE lines compared to the WT. Moreover, the amount of aliphatic suberin content (fatty acids, specifically very-long-chain fatty acids (VLCFA) of C24 and C26 as well as sterols) in roots of Arabidopsis was doubled in OE lines relative to WT. The authors proposed that AtANAC046 primarily mediates aliphatic suberin biosynthesis in Arabidopsis roots [147].

\subsubsection{WRKY Transcription Factors}

While a role for WRKY TFs in suberization has not been explicitly demonstrated, their ability to activate transcription of phenylpropanoid genes involved in SPPD monomer synthesis, like StTHT [148], offer insight into a possible regulatory mechanism for stressinduced phenolic suberin production. Indeed, WRKY-domain TFs are involved in many plant processes including responses to both biotic and abiotic stresses [148,162-166]. For example, Yogendra et al. [148] characterized StWRKY1 as a regulator of pathogen-induced hydroxycinnamic acid amide deposition into secondary cell walls of aerial potato tissues. The authors used metabolomic comparisons between pathogen-inoculated late blight (Phytophthora infestans)-resistant and -susceptible potato cultivars to elucidate phenylpropanoid 
metabolites linked to resistance, and identified the genes required for their biosynthesis, 4-coumarate:CoA ligase (St4CL) and tyramine hydroxycinnamoyl transferase (StTHT). StWRKY1 was shown to physically interact with target DNA, and its function was further validated using a gene silencing approach. StWRKY1 binds to the promoter region of its target phenylpropanoid biosynthetic genes, St4CL and StTHT, to activate transcription. Gene silencing of StWRKY1 caused a significant decrease in hydroxycinnamic acid amide abundance and a severe reduction in resistance to the late blight causing pathogen P. infestans [148]. These results revealed a role for StWRKY1 in the regulation of downstream genes during hydroxycinnamic acid amides synthesis in stress-induced metabolism, and implicate it in the formation of wound suberin.

\subsection{Interaction between Phytohormones and Transcription Factors}

In the context of suberin biosynthesis, linkage, and deposition, a picture is emerging in which several TFs coordinately regulate suberin-specific gene expression under various developmental and stress conditions, in conjunction with specific phytohormones (especially ABA). Recent evidence supports the interaction between the TF-mediated developmental programs and stress hormone-mediated pathways in the regulation of Arabidopsis root endodermis suberization [143,167]. For example, the SHORT-ROOT (AtSHR) transcription factor, and AtMYB36 are organized into a sub-network that regulates CS formation [168,169]. Several of the genes regulated by AtSHR and AtMYB36 include other MYB transcription factor genes including MYB9 [85], MYB107 [85,170], MYB41 [38], MYB39 [144,171], and MYB93 [111]. Wang et al. [171] illustrated that MYB39 and MYB93 are co-regulated by SHR and MYB36. They concluded that MYB39 could function as a potential downstream hub connecting the SHR regulatory network and ABA pathways to promote suberization [143]. Similarly, Shukla et al. [167] recently demonstrated a direct role for a small suite of MYB TFs, namely AtMYB41, AtMYB53, AtMYB92, and AtMYB93, in Arabidopsis CS suberization in response to ABA and the SGN3/CIF pathway (see Section 4.4, below).

In kiwifruit, expression of several TFs has been linked to ABA [142,145,155,156]. Specifically, AchnMYB41, AchnMYB107, and AchnMYC2 expression was enhanced in response to ABA, whereas FD suppressed the expression of genes encoding these TFs [156]. The overexpression of these TFs in $N$. benthamiana leaves led to the upregulation of aliphatic suberin synthesis genes and an increase in the amounts of primary alcohols, $\alpha, \omega$-diacids, $\omega$-hydroxyacids, and fatty acids [156]. In contrast, AcnhMYB4 was found to suppress the expression of aliphatic suberin biosynthetic genes AchnCYP86A1 and AchnFAR and reduce accumulation of $\omega$-hydroxyacids and primary alcohols in wounded kiwifruit and in a N. benthamiana expression system [142].

Activator and suppressor TFs appear to work in concert to fine-tune regulation, either for both phenylpropanoid and fatty acid metabolic pathways, or solely aliphatic suberin deposition. The majority of defined suberin-related TFs are transcriptional activators, including AtMYB9, AtMYB39, AtMYB41, AtMYB92, AtMYB107, and AtANAC046 in Arabidopsis thaliana, StMYB74 and StMYB102 in potato, MdMYB93 in apple, QsMYB1 in Quercus suber and AchnABF2, AchnMYB41, AchnMYB107, and AchnMYC2 in kiwifruit (summarized in Table 2). In contrast, StNAC103 in potato and AchnMYB4 in kiwifruit repress the biosynthesis of aliphatic suberin, as well as the cross-linkage of aliphatics with ferulic acid, and its export. Interestingly, StNAC103 gene expression is induced by ABA, whereas AchnMYB4 is inhibited by exogenous ABA application [83,156]. AtMYB107 and AtMYB9 act together to regulate both SPPD and SPAD metabolism [85].

TFs function within highly complex regulatory networks, which may involve phytohormonesignaling, to control suberin-related metabolism and transport in different species, during normal development and under stress conditions. Further research is required to fully elucidate the regulatory oversight of differential suberin-related pathway induction during the wound response, including the timing of biosynthesis, the spatial organization of deposited suberin, and the fine-tuning that is likely required to harmonize this process. 


\subsection{A Role for Casparian Strip Membrane Domain Proteins}

Roots absorb nutrients from the soil and transport them through the epidermis, cortex and endodermis layers to reach to the vasculature (stele). Transport of nutrients to the stele takes place via two major pathways. The first is the apoplastic pathway, in which solutes diffuse freely through the apoplast. The second is the symplastic pathway, where solutes move cell-to-cell through the plasmodesmata [172]. The endodermis is the innermost cell layer that surrounds the vasculature [94]. During differentiation, the endodermis undergoes specialized cell wall modifications including the deposition of lignin-like poly(phenolic) and aliphatic suberin polymers in a continuous band in their radial walls, forming the Casparian strip (CS) in what is referred to as a State I endodermis [151]. After formation and maturation of the CS, the endodermis undergoes a second step of differentiation, forming a State II endodermis in which lamellar suberin (primarily aliphatic suberin monomers) is deposited between the primary cell wall and the plasma membrane and completely covers the cell surface [173]. Therefore, it seems that the poly(phenolic) and poly(aliphatic) suberin domains of the endodermis are regulated separately and in a spatiotemporal manner. Initial deposition of lignin-like poly(phenolic) components delineates the formation of the CS, building a ring-like structure that connects the radial walls of each endodermal cell to its neighboring cells, to form a barrier to diffusion through the apoplast $[40,65,174]$. In Arabidopsis mutants defective in aliphatic suberin deposition, the presence of the poly(phenolic) domain of suberin alone appears to be sufficient to form a functional CS [40]. This does not preclude aliphatic suberin as an integral component of the CS, however, and clear chemical evidence has been presented in support of significant levels of aliphatic suberin in State I endodermal tissues of some species, including maize [151] and soybean [152]. At early stages of endodermal differentiation in Arabidopsis (i.e., the State I-II transition), a patchy distribution of aliphatic suberin precedes complete suberization of endodermal cells, while fully differentiated mature endodermal cells have a continuous suberization zone [172].

Roppolo et al. [175] identified a family of transmembrane proteins called Casparian strip membrane domain proteins (CASPs). CASP deposition predicts the site of CS formation in the endodermal cell wall [175]. CASP1-5 are members of this family in Arabidopsis, and their aggregation marks a membrane domain that attaches to the cell wall, excludes most other plasma membrane proteins and delineates the location of the CS $[65,175,176]$. CASP proteins appear to form a scaffold that acts as a platform for regulation and deposition of the CS poly(phenolic) domain $[67,175]$. The precise deposition of the CS poly(phenolic) domain requires a signaling pathway involving a cytoplasmic receptor-like kinase SCHENGEN1 (AtSGN1) and the receptor SCHENGEN3 (AtSGN3), which control the spatial production of reactive oxygen species (ROS) via the activation of the respiratory burst oxidase homolog F (RBOHF) NADPH oxidases [65,177-179]. Phenolic polymerization requires the localized action of a peroxidase (AtPER64) [66] and a dirigent-like protein (AtESB1) [67]. Thus, the SGN3 signaling pathway operates in parallel with a network of transcriptional factors involving SHR-SCR and AtMYB36 that controls endodermal differentiation [180,181].

CASPs are found in many plant species [86,182], where their function may be conserved. In potato, two orthologs of Casparian strip associated Arabidopsis CASPs, StCASP1like/StCASP8 and StCASP1B2-like/StCASP9, are expressed during tuber periderm maturation (i.e., in suberizing potato skin) along with a cutin synthase-like GDSL lipase/esterase gene (StGDSL-like) [86]. It is tempting to speculate that CASPs and GDSL-like proteins may also be involved in coordinating the deposition of suberin in response to wounding. For example, Woolfson [37] demonstrated that these two putative CASP genes identified in tuber phellem were also upregulated by wounding in potato tubers, along with other suberin-associated genes [37]. Such a role for CASP genes outside CS formation is not unprecedented as AtCASPL1B2 (a putative homolog of StCASP1B2-like/StCASP9) was downregulated in myb9 myb107 mutant seed coats [85]. StCASP1-like/StCASP8 was expressed in the same temporal pattern as genes required for SPAD assembly and co- 
incided with the upregulation of aliphatic monomer biosynthesis genes, along with the putative GDSL-type gene StGDSL.7 [37]. This suggests that StCASP1-like/StCASP8 and StGDSL.7 may act to regulate aliphatic monomer incorporation into the SPAD in potato at a later time than when genes are first expressed and soluble monomers accumulate. Moreover, StCASP1-like/StCASP8 could act as a mediator between SPPD and SPAD assembly activities, possibly by orchestrating the linkage of the two domains. Additionally, StCASP1B2-like/StCASP9 and another putative GDSL-type gene, StGDSL.6, followed temporal expression patterns similar to aliphatic metabolism genes after wounding, and thus could be candidates for involvement in SPAD assembly [37].

New candidate proteins involved in CS formation were identified during characterization of other AtMYB36-regulated genes [183] in Arabidopsis, including a gene encoding a copper-containing protein Uclacyanin1 (UCC1) that localizes to the CS. UCC1 constitutes a central CS nanodomain while other CS-located proteins are accumulated at the periphery of the CS. The loss-of-function of two uclacyanins (UCC1 and UCC2) decreased poly(phenolic) deposition, specifically in the central CS nanodomain and led to endodermal permeability and altered mineral nutrient homeostasis [183]. This result suggests that CS biosynthetic machinery involved in the polymerization of phenolics is nano-compartmentalized.

CASPs are essential for the precise localization of the CS by forming a scaffold domain (i.e., Casparian strip domain) within the plasma membrane that predicts the formation of the CS. Indeed, the Casparian strip domain provides a protein platform that allows localization of various enzymes like peroxidases, reactive-oxygen species-producing enzymes, transporters or combinations of these. Despite new understanding of the underlying mechanisms leading to CS initialization, many questions remain about the complex regulatory network underlying CS formation. Similarly, a more general role for CASPs in delineating sites for suberin deposition may exist, considering their wound-inducibility in potato tubers. Further studies on the identification and characterization of the CASPs and their associated proteins will offer more insights into the molecular mechanisms that determine the development, early differentiation, and CS formation in endodermal cells, and suberin deposition in general.

\section{Conclusions}

Timely and effective suberization is vital to prevent water loss and infection, as well as healing wounds incurred during harvest and post-harvest handling and storage. This review provides insight into the molecular-genetic pathways leading to the biosynthesis and regulation of suberin deposition. There remains a need to elucidate the differential and temporal regulation of phenolic and aliphatic metabolic pathways required for suberin development. Recent investigations into the regulatory oversight of suberization have revealed the involvement of phytohormones including ABA, transcription factors that interact with ABA and biosynthetic genes, and novel candidates that may coordinate suberin domain assembly and linkage, such as CASPs. Collectively, these findings advance our fundamental understanding of what orchestrates the suberization process, and the potential to improve valuable agricultural products through the targeted engineering of crops with improved stress resistance traits, such as enhanced drought and pathogen resistance, or in identifying molecular markers to assist in the selection of crops with improved agronomic traits and post-harvest storability.

Author Contributions: Conceptualization, K.N.W., M.A.B.; writing-original draft preparation, K.N.W. and M.E.; writing-review and editing, K.N.W., M.E., M.A.B.; funding acquisition, M.A.B. All authors have read and agreed to the published version of the manuscript.

Funding: Research included from the M.A.B. lab and the APC were funded by a Natural Sciences and Engineering Research Council (NSERC) Discovery Grant [04228-2017 RGPIN].

Institutional Review Board Statement: Not applicable.

Informed Consent Statement: Not applicable. 
Data Availability Statement: Not applicable.

Conflicts of Interest: The authors declare no conflict of interest.

\section{References}

1. Croteau, R.; Kutchan, T.M.; Lewis, N.G. Natural products (secondary metabolites). In Biochemistry and Molecular Biology of Plants, 2nd ed.; Buchanan, B., Gruissem, W., Jones, R.L., Eds.; American Society of Plant Physiologists: Rockville, MD, USA, 2000; Volume 24, pp. 1250-1319.

2. Lü, S.; Song, T.; Kosma, D.K.; Parsons, E.P.; Rowland, O.; Jenks, M.A. Arabidopsis CER8 encodes LONG-CHAIN ACYL-COA SYNTHETASE 1 (LACS1) that has overlapping functions with LACS2 in plant wax and cutin synthesis. Plant J. 2009, 59, 553-564. [CrossRef]

3. Edreva, A.; Velikova, V.; Tsonev, T.; Dagnon, S.; Gürel, A.; Aktaş, L.; Gesheva, E. Stress-protective role of secondary metabolites: Diversity of functions and mechanisms. Gen. Appl. Plant Physiol. 2008, 34, 67-78.

4. Bernards, M.A. Demystifying suberin. Can. J. Bot. 2002, 80, 227-240. [CrossRef]

5. Pollard, M.; Beisson, F.; Li, Y.; Ohlrogge, J.B. Building lipid barriers: Biosynthesis of cutin and suberin. Trends Plant Sci. 2008, 13, 236-246. [CrossRef]

6. Schreiber, L. Transport barriers made of cutin, suberin and associated waxes. Trends Plant Sci. 2010, 15, 546-553. [CrossRef] [PubMed]

7. Soler, M.; Serra, O.; Molinas, M.; Huguet, G.; Fluch, S.; Figueras, M. A genomic approach to suberin biosynthesis and cork differentiation. Plant Physiol. 2007, 144, 419-431. [CrossRef]

8. Beisson, F.; Li-Beisson, Y.; Pollard, M. Solving the puzzles of cutin and suberin polymer biosynthesis. Curr. Opin. Plant Biol. 2012, 15, 329-337. [CrossRef]

9. Li-Beisson, Y.; Shorrosh, B.; Beisson, F.; Andersson, M.X.; Arondel, V.; Bates, P.D.; Baud, S.; Bird, D.; DeBono, A.; Durrett, T.P. Acyl-lipid metabolism. Arab. Book 2013, 11, e0161. [CrossRef]

10. Serra, O.; Soler, M.; Hohn, C.; Franke, R.; Schreiber, L.; Prat, S.; Molinas, M.; Figueras, M. Silencing of StKCS6 in potato periderm leads to reduced chain lengths of suberin and wax compounds and increased peridermal transpiration. J. Exp. Bot. 2009, 60, 697-707. [CrossRef]

11. Franke, R.B.; Dombrink, I.; Schreiber, L. Suberin goes genomics: Use of a short living plant to investigate a long lasting polymer. Front. Plant Sci. 2012, 3, 4. [CrossRef]

12. Lee, S.B.; Jung, S.J.; Go, Y.S.; Kim, H.U.; Kim, J.K.; Cho, H.J.; Park, O.K.; Suh, M.C. Two Arabidopsis 3-ketoacyl CoA synthase genes, KCS20 and KCS2/DAISY, are functionally redundant in cuticular wax and root suberin biosynthesis, but differentially controlled by osmotic stress. Plant J. 2009, 60, 462-475. [CrossRef] [PubMed]

13. Serra, O.; Soler, M.; Hohn, C.; Sauveplane, V.; Pinot, F.; Franke, R.; Schreiber, L.; Prat, S.; Molinas, M.; Figueras, M. CYP86A33targeted gene silencing in potato tuber alters suberin composition, distorts suberin lamellae, and impairs the periderm's water barrier function. Plant Physiol. 2009, 149, 1050-1060. [CrossRef] [PubMed]

14. Bjelica, A.; Haggitt, M.L.; Woolfson, K.N.; Lee, D.P.; Makhzoum, A.B.; Bernards, M.A. Fatty acid w-hydroxylases from Solanum tuberosum. Plant Cell Rep. 2016, 35, 2435-2448. [CrossRef]

15. Höfer, R.; Briesen, I.; Beck, M.; Pinot, F.; Schreiber, L.; Franke, R. The Arabidopsis cytochrome P450 CYP86A1 encodes a fatty acid $\omega$-hydroxylase involved in suberin monomer biosynthesis. J. Exp. Bot. 2008, 59, 2347-2360. [CrossRef]

16. Compagnon, V.; Diehl, P.; Benveniste, I.; Meyer, D.; Schaller, H.; Schreiber, L.; Franke, R.; Pinot, F. CYP86B1 is required for very long chain $\omega$-hydroxyacid and $\alpha$, $\omega$-dicarboxylic acid synthesis in root and seed suberin polyester. Plant Physiol. 2009, 150, 1831-1843. [CrossRef] [PubMed]

17. Molina, I.; Li-Beisson, Y.; Beisson, F.; Ohlrogge, J.B.; Pollard, M. Identification of an Arabidopsis feruloyl-coenzyme A transferase required for suberin synthesis. Plant Physiol. 2009, 151, 1317-1328. [CrossRef]

18. Domergue, F.; Vishwanath, S.J.; Joubès, J.; Ono, J.; Lee, J.A.; Bourdon, M.; Alhattab, R.; Lowe, C.; Pascal, S.; Lessire, R. Three Arabidopsis fatty acyl-coenzyme A reductases, FAR1, FAR4, and FAR5, generate primary fatty alcohols associated with suberin deposition. Plant Physiol. 2010, 153, 1539-1554. [CrossRef]

19. Vishwanath, S.J.; Kosma, D.K.; Pulsifer, I.P.; Scandola, S.; Pascal, S.; Joubès, J.; Dittrich-Domergue, F.; Lessire, R.; Rowland, O.; Domergue, F. Suberin-associated fatty alcohols in Arabidopsis: Distributions in roots and contributions to seed coat barrier properties. Plant Physiol. 2013, 163, 1118-1132. [CrossRef]

20. Beisson, F.; Li, Y.; Bonaventure, G.; Pollard, M.; Ohlrogge, J.B. The acyltransferase GPAT5 is required for the synthesis of suberin in seed coat and root of Arabidopsis. Plant Cell 2007, 19, 351-368. [CrossRef]

21. Li, Y.; Beisson, F.; Koo, A.J.; Molina, I.; Pollard, M.; Ohlrogge, J. Identification of acyltransferases required for cutin biosynthesis and production of cutin with suberin-like monomers. Proc. Natl. Acad. Sci. USA 2007, 104, 18339-18344. [CrossRef]

22. Gou, J.-Y.; Yu, X.-H.; Liu, C.-J. A hydroxycinnamoyltransferase responsible for synthesizing suberin aromatics in Arabidopsis. Proc. Natl. Acad. Sci. USA 2009, 106, 18855-18860. [CrossRef]

23. Serra, O.; Hohn, C.; Franke, R.; Prat, S.; Molinas, M.; Figueras, M. A feruloyl transferase involved in the biosynthesis of suberin and suberin-associated wax is required for maturation and sealing properties of potato periderm. Plant J. 2010, 62, 277-290. [CrossRef] [PubMed] 
24. Boher, P.; Serra, O.; Soler, M.; Molinas, M.; Figueras, M. The potato suberin feruloyl transferase FHT which accumulates in the phellogen is induced by wounding and regulated by abscisic and salicylic acids. J. Exp. Bot. 2013, 64, 3225-3236. [CrossRef] [PubMed]

25. Landgraf, R.; Smolka, U.; Altmann, S.; Eschen-Lippold, L.; Senning, M.; Sonnewald, S.; Weigel, B.; Frolova, N.; Strehmel, N.; Hause, G. The ABC transporter ABCG1 is required for suberin formation in potato tuber periderm. Plant Cell 2014, 26, 3403-3415. [CrossRef] [PubMed]

26. Yadav, V.; Molina, I.; Ranathunge, K.; Castillo, I.Q.; Rothstein, S.J.; Reed, J.W. ABCG transporters are required for suberin and pollen wall extracellular barriers in Arabidopsis. Plant Cell 2014, 26, 3569-3588. [CrossRef]

27. Tanios, S.; Thangavel, T.; Eyles, A.; Tegg, R.S.; Nichols, D.S.; Corkrey, R.; Wilson, C.R. Suberin deposition in potato periderm: A novel resistance mechanism against tuber greening. New Phytol. 2020, 225, 1273-1284. [CrossRef] [PubMed]

28. Kolattukudy, P. Biopolyester membranes of plants: Cutin and suberin. Science 1980, 208, 990-1000. [CrossRef]

29. Graça, J. Suberin: The biopolyester at the frontier of plants. Front. Chem. 2015, 3, 62. [CrossRef]

30. Mattinen, M.-L.; Filpponen, I.; Järvinen, R.; Li, B.; Kallio, H.; Lehtinen, P.; Argyropoulos, D. Structure of the polyphenolic component of suberin isolated from potato (Solanum tuberosum var. Nikola). J. Agric. Food Chem. 2009, 57, 9747-9753. [CrossRef]

31. Stark, R.E.; Garbow, J.R. Nuclear magnetic resonance relaxation studies of plant polyester dynamics. 2. Suberized potato cell wall. Macromolecules 1992, 25, 149-154. [CrossRef]

32. Bernards, M.A.; Lopez, M.L.; Zajicek, J.; Lewis, N.G. Hydroxycinnamic acid-derived polymers constitute the polyaromatic domain of suberin $\left(^{*}\right)$. J. Biol. Chem. 1995, 270, 7382-7386. [CrossRef] [PubMed]

33. Bernards, M.A.; Lewis, N.G. The macromolecular aromatic domain in suberized tissue: A changing paradigm. Phytochemistry 1998, 47, 915-933. [CrossRef]

34. Bernards, M.A.; Razem, F.A. The poly (phenolic) domain of potato suberin: A non-lignin cell wall bio-polymer. Phytochemistry 2001, 57, 1115-1122. [CrossRef]

35. Yang, W.-L.; Bernards, M.A. Metabolite profiling of potato (Solanum tuberosum L.) tubers during wound-induced suberization Metabolomics 2007, 3, 147-159. [CrossRef]

36. Woolfson, K.N.; Haggitt, M.L.; Zhang, Y.; Kachura, A.; Bjelica, A.; Rey Rincon, M.A.; Kaberi, K.M.; Bernards, M.A. Differential induction of polar and non-polar metabolism during wound-induced suberization in potato (Solanum tuberosum L.) tubers. Plant J. 2018, 93, 931-942. [CrossRef] [PubMed]

37. Woolfson, K.N. Suberin Biosynthesis and Deposition in the Wound-Healing Potato (Solanum tuberosum L.) Tuber Model. Ph.D. Thesis, University of Western Ontario, London, ON, Canada, 2018.

38. Kosma, D.K.; Murmu, J.; Razeq, F.M.; Santos, P.; Bourgault, R.; Molina, I.; Rowland, O. At MYB 41 activates ectopic suberin synthesis and assembly in multiple plant species and cell types. Plant J. 2014, 80, 216-229. [CrossRef]

39. Andersen, T.G.; Molina, D.; Kilian, J.; Franke, R.B.; Ragni, L.; Geldner, N. Tissue-autonomous phenylpropanoid production is essential for establishment of root barriers. Curr. Biol. 2021, 31, 965-977.e965. [CrossRef]

40. Naseer, S.; Lee, Y.; Lapierre, C.; Franke, R.; Nawrath, C.; Geldner, N. Casparian strip diffusion barrier in Arabidopsis is made of a lignin polymer without suberin. Proc. Natl. Acad. Sci. USA 2012, 109, 10101-10106. [CrossRef]

41. Holloway, P.J. Some variations in the composition of suberin from the cork layers of higher plants. Phytochemistry 1983, 22, 495-502. [CrossRef]

42. Graça, J.; Pereira, H. Cork suberin: A glyceryl based polyester. Holzforschung 1997, 51, 225-234. [CrossRef]

43. Nawrath, C.; Schreiber, L.; Franke, R.B.; Geldner, N.; Reina-Pinto, J.J.; Kunst, L. Apoplastic diffusion barriers in Arabidopsis. Arab. Book 2013, 11, e0167. [CrossRef] [PubMed]

44. Riley, R.G.; Kolattukudy, P.E. Evidence for covalently attached p-coumaric acid and ferulic acid in cutins and suberins. Plant Physiol. 1975, 56, 650-654. [CrossRef] [PubMed]

45. Cottle, W.; Kolattukudy, P. Abscisic acid stimulation of suberization: Induction of enzymes and deposition of polymeric components and associated waxes in tissue cultures of potato tuber. Plant Physiol. 1982, 70, 775-780. [CrossRef] [PubMed]

46. Moire, L.; Schmutz, A.; Buchala, A.; Yan, B.; Stark, R.E.; Ryser, U. Glycerol is a suberin monomer. New experimental evidence for an old hypothesis. Plant Physiol. 1999, 119, 1137-1146. [CrossRef]

47. Schmutz, A.; Jenny, T.; Ryser, U. A caffeoyl-fatty acid-glycerol ester from wax associated with green cotton fibre suberin. Phytochemistry 1994, 36, 1343-1346. [CrossRef]

48. Graça, J.; Pereira, H. Glyceryl-acyl and aryl-acyl dimers in Pseudotsuga menziesii bark suberin. Holzforschung 1999, $53,397$. [CrossRef]

49. Graça, J.; Pereira, H. Diglycerol alkenedioates in suberin: Building units of a poly(acylglycerol) polyester. Biomacromolecules 2000, 1, 519-522. [CrossRef]

50. Matzke, K.; Riederer, M. A comparative study into the chemical constitution of cutins and suberins from Picea abies (L.) Karst., Quercus robur L., and Fagus sylvatica L. Planta 1991, 185, 233-245. [CrossRef]

51. Zeier, J.; Schreiber, L. Comparative investigation of primary and tertiary endodermal cell walls isolated from the roots of five monocotyledoneous species: Chemical composition in relation to fine structure. Planta 1998, 206, 349-361. [CrossRef]

52. Havir, E.A.; Hanson, K.R. [72a] l-phenylalanine ammonia-lyase (potato tubers). Meth. Enzymol. 1970, 17, 575-581.

53. Wang-Pruski, G.; Cantal, S. Cloning and expression of cinnamic acid 4-hydroxylase in potato, a gene related to after-cooking darkening. Acta Physiol. Plant 2004, 26, 60-61. 
54. Schneider, K.; Hövel, K.; Witzel, K.; Hamberger, B.; Schomburg, D.; Kombrink, E.; Stuible, H.-P. The substrate specificitydetermining amino acid code of 4-coumarate: CoA ligase. Proc. Natl. Acad. Sci. USA 2003, 100, 8601-8606. [CrossRef]

55. Hoffmann, L.; Maury, S.; Martz, F.; Geoffroy, P.; Legrand, M. Purification, cloning, and properties of an acyltransferase controlling shikimate and quinate ester intermediates in phenylpropanoid metabolism. J. Biol. Chem. 2003, 278, 95-103. [CrossRef] [PubMed]

56. Knollenberg, B.J.; Liu, J.; Yu, S.; Lin, H.; Tian, L. Cloning and functional characterization of a p-coumaroyl quinate/shikimate 3'-hydroxylase from potato (Solanum tuberosum). Biochem. Biophys. Res. Commun. 2018, 496, 462-467. [CrossRef]

57. Do, C.-T.; Pollet, B.; Thévenin, J.; Sibout, R.; Denoue, D.; Barrière, Y.; Lapierre, C.; Jouanin, L. Both caffeoyl coenzyme A 3-O-methyltransferase 1 and caffeic acid $O$-methyltransferase 1 are involved in redundant functions for lignin, flavonoids and sinapoyl malate biosynthesis in Arabidopsis. Planta 2007, 226, 1117-1129. [CrossRef] [PubMed]

58. Meyer, K.; Cusumano, J.C.; Somerville, C.; Chapple, C. Ferulate-5-hydroxylase from Arabidopsis thaliana defines a new family of cytochrome P450-dependent monooxygenases. Proc. Natl. Acad. Sci. USA 1996, 93, 6869-6874. [CrossRef] [PubMed]

59. Humphreys, J.M.; Hemm, M.R.; Chapple, C. New routes for lignin biosynthesis defined by biochemical characterization of recombinant ferulate 5-hydroxylase, a multifunctional cytochrome P450-dependent monooxygenase. Proc. Natl. Acad. Sci. USA 1999, 96, 10045-10050. [CrossRef] [PubMed]

60. Negrel, J.; Javelle, F.; Paynot, M. Wound-induced tyramine hydroxycinnamoyl transferase in potato (Solanum tuberosum) tuber discs. J. Plant Physiol. 1993, 142, 518-524. [CrossRef]

61. Larsen, K. Molecular cloning and characterization of cDNAs encoding cinnamoyl CoA reductase (CCR) from barley (Hordeum vulgare) and potato (Solanum tuberosum). J. Plant Physiol. 2004, 161, 105-112. [CrossRef]

62. Bernards, M.A.; Fleming, W.D.; Llewellyn, D.B.; Priefer, R.; Yang, X.; Sabatino, A.; Plourde, G.L. Biochemical characterization of the suberization-associated anionic peroxidase of potato. Plant Physiol. 1999, 121, 135-146. [CrossRef]

63. Razem, F.A.; Bernards, M.A. Hydrogen peroxide is required for poly(phenolic) domain formation during wound-induced suberization. J. Agric. Food Chem. 2002, 50, 1009-1015. [CrossRef] [PubMed]

64. Razem, F.A.; Bernards, M.A. Reactive oxygen species production in association with suberization: Evidence for an NADPHdependent oxidase. J. Exp. Bot. 2003, 54, 935-941. [CrossRef] [PubMed]

65. Alassimone, J.; Naseer, S.; Geldner, N. A developmental framework for endodermal differentiation and polarity. Proc. Natl. Acad. Sci. USA 2010, 107, 5214-5219. [CrossRef] [PubMed]

66. Lee, Y.; Rubio, M.C.; Alassimone, J.; Geldner, N. A mechanism for localized lignin deposition in the endodermis. Cell 2013, 153, 402-412. [CrossRef]

67. Hosmani, P.S.; Kamiya, T.; Danku, J.; Naseer, S.; Geldner, N.; Guerinot, M.L.; Salt, D.E. Dirigent domain-containing protein is part of the machinery required for formation of the lignin-based Casparian strip in the root. Proc. Natl. Acad. Sci. USA 2013, 110, 14498-14503. [CrossRef]

68. Rojas-Murcia, N.; Hématy, K.; Lee, Y.; Emonet, A.; Ursache, R.; Fujita, S.; De Bellis, D.; Geldner, N. High-order mutants reveal an essential requirement for peroxidases but not laccases in Casparian strip lignification. Proc. Natl. Acad. Sci. USA 2020, 117, 29166-29177. [CrossRef]

69. Quiroga, M.; Guerrero, C.; Botella, M.A.; Barceló, A.; Amaya, I.; Medina, M.I.; Alonso, F.J.; de Forchetti, S.M.; Tigier, H.; Valpuesta, V. A tomato peroxidase involved in the synthesis of lignin and suberin. Plant Physiol. 2000, 122, 1119-1128. [CrossRef]

70. Franke, R.; Höfer, R.; Briesen, I.; Emsermann, M.; Efremova, N.; Yephremov, A.; Schreiber, L. The DAISY gene from Arabidopsis encodes a fatty acid elongase condensing enzyme involved in the biosynthesis of aliphatic suberin in roots and the chalazamicropyle region of seeds. Plant J. 2009, 57, 80-95. [CrossRef]

71. Beaudoin, F.; Wu, X.; Li, F.; Haslam, R.P.; Markham, J.E.; Zheng, H.; Napier, J.A.; Kunst, L. Functional characterization of the Arabidopsis $\beta$-ketoacyl-coenzyme A reductase candidates of the fatty acid elongase. Plant Physiol. 2009, 150, 1174-1191. [CrossRef]

72. Bach, L.; Michaelson, L.V.; Haslam, R.; Bellec, Y.; Gissot, L.; Marion, J.; Da Costa, M.; Boutin, J.-P.; Miquel, M.; Tellier, F. The very-long-chain hydroxy fatty acyl-CoA dehydratase PASTICCINO2 is essential and limiting for plant development. Proc. Natl. Acad. Sci. USA 2008, 105, 14727-14731. [CrossRef]

73. Zheng, H.; Rowland, O.; Kunst, L. Disruptions of the Arabidopsis enoyl-CoA reductase gene reveal an essential role for very-long-chain fatty acid synthesis in cell expansion during plant morphogenesis. Plant Cell 2005, 17, 1467-1481. [CrossRef] [PubMed]

74. Benveniste, I.; Tijet, N.; Adas, F.; Philipps, G.; Salaün, J.-P.; Durst, F. CYP86A1 from Arabidopsis thaliana encodes a cytochrome p450-dependent fatty acid omega-hydroxylase. Biochem. Biophys. Res. Commun. 1998, 243, 688-693. [CrossRef] [PubMed]

75. Agrawal, V.P.; Kolattukudy, P. Purification and characterization of a wound-induced $\omega$-hydroxyfatty acid: NADP oxidoreductase from potato tuber disks (Solanum tuberosum L.). Arch. Biochem. Biophys. 1978, 191, 452-465. [CrossRef]

76. Agrawal, V.P.; Kolattukudy, P. Mechanism of action of a wound-induced $\omega$-hydroxyfatty acid: NADP oxidoreductase isolated from potato tubers (Solanum tuberosum L). Arch. Biochem. Biophys. 1978, 191, 466-478. [CrossRef]

77. Agrawal, V.P.; Kolattukudy, P. Biochemistry of suberization: $\omega$-hydroxyacid oxidation in enzyme preparations from suberizing potato tuber disks. Plant Physiol. 1977, 59, 667-672. [CrossRef]

78. Le Bouquin, R.; Skrabs, M.; Kahn, R.; Benveniste, I.; Salaün, J.P.; Schreiber, L.; Durst, F.; Pinot, F. CYP94A5, a new cytochrome P450 from Nicotiana tabacum is able to catalyze the oxidation of fatty acids to the $\omega$-alcohol and to the corresponding diacid. Eur. J. Biochem. 2001, 268, 3083-3090. [CrossRef] 
79. Kandel, S.; Sauveplane, V.; Compagnon, V.; Franke, R.; Millet, Y.; Schreiber, L.; Werck-Reichhart, D.; Pinot, F. Characterization of a methyl jasmonate and wounding-responsive cytochrome P450 of Arabidopsis thaliana catalyzing dicarboxylic fatty acid formation in vitro. FEBS J. 2007, 274, 5116-5127. [CrossRef]

80. Bernard, A.; Domergue, F.; Pascal, S.; Jetter, R.; Renne, C.; Faure, J.-D.; Haslam, R.P.; Napier, J.A.; Lessire, R.; Joubès, J. Reconstitution of plant alkane biosynthesis in yeast demonstrates that Arabidopsis ECERIFERUM1 and ECERIFERUM3 are core components of a very-long-chain alkane synthesis complex. Plant Cell 2012, 24, 3106-3118. [CrossRef]

81. Yang, W.; Simpson, J.P.; Li-Beisson, Y.; Beisson, F.; Pollard, M.; Ohlrogge, J.B. A land-plant-specific glycerol-3-phosphate acyltransferase family in Arabidopsis: Substrate specificity, sn-2 preference, and evolution. Plant Physiol. 2012, 160, 638-652. [CrossRef]

82. Shanmugarajah, K.; Linka, N.; Gräfe, K.; Smits, S.H.J.; Weber, A.P.M.; Zeier, J.; Schmidtt, L. ABCG1 contributes to suberin formation in Arabidopsis thaliana roots. Sci. Rep. 2019, 9, 11381. [CrossRef]

83. Verdaguer, R.; Soler, M.; Serra, O.; Garrote, A.; Fernández, S.; Company-Arumí, D.; Anticó, E.; Molinas, M.; Figueras, M. Silencing of the potato StNAC103 gene enhances the accumulation of suberin polyester and associated wax in tuber skin. J. Exp. Bot. 2016, 67, 5415-5427. [CrossRef] [PubMed]

84. Shiono, K.; Ando, M.; Nishiuchi, S.; Takahashi, H.; Watanabe, K.; Nakamura, M.; Matsuo, Y.; Yasuno, N.; Yamanouchi, U.; Fujimoto, M. RCN1/OsABCG5, an ATP-binding cassette (ABC) transporter, is required for hypodermal suberization of roots in rice (Oryza sativa). Plant J. 2014, 80, 40-51. [CrossRef] [PubMed]

85. Lashbrooke, J.; Cohen, H.; Levy-Samocha, D.; Tzfadia, O.; Panizel, I.; Zeisler, V.; Massalha, H.; Stern, A.; Trainotti, L.; Schreiber, L. MYB107 and MYB9 homologs regulate suberin deposition in angiosperms. Plant Cell 2016, 28, 2097-2116. [CrossRef]

86. Vulavala, V.K.; Fogelman, E.; Rozental, L.; Faigenboim, A.; Tanami, Z.; Shoseyov, O.; Ginzberg, I. Identification of genes related to skin development in potato. Plant Mol. Biol. 2017, 94, 481-494. [CrossRef] [PubMed]

87. Vogt, T. Phenylpropanoid biosynthesis. Mol. Plant 2010, 3, 2-20. [CrossRef] [PubMed]

88. Biała, W.; Jasiński, M. The phenylpropanoid case-It is transport that matters. Front. Plant Sci. 2018, 9, 1610. [CrossRef] [PubMed]

89. Yogendra, K.N.; Pushpa, D.; Mosa, K.A.; Kushalappa, A.C.; Murphy, A.; Mosquera, T. Quantitative resistance in potato leaves to late blight associated with induced hydroxycinnamic acid amides. Funct. Integr. 2014, 14, 285-298. [CrossRef]

90. Hagel, J.M.; Facchini, P.J. Elevated tyrosine decarboxylase and tyramine hydroxycinnamoyltransferase levels increase woundinduced tyramine-derived hydroxycinnamic acid amide accumulation in transgenic tobacco leaves. Planta 2005, 221, 904-914. [CrossRef]

91. Bernards, M.A.; Susag, L.M.; Bedgar, D.L.; Anterola, A.M.; Lewis, N.G. Induced phenylpropanoid metabolism during suberization and lignification: A comparative analysis. J. Plant Physiol. 2000, 157, 601-607. [CrossRef]

92. Espelie, K.E.; Franceschi, V.R.; Kolattukudy, P. Immunocytochemical localization and time course of appearance of an anionic peroxidase associated with suberization in wound-healing potato tuber tissue. Plant Physiol. 1986, 81, 487-492. [CrossRef]

93. Nawrath, C. The biopolymers cutin and suberin. Arab. Book 2002, 1, e0021. [CrossRef] [PubMed]

94. Schreiber, L.; Hartmann, K.; Skrabs, M.; Zeier, J. Apoplastic barriers in roots: Chemical composition of endodermal and hypodermal cell walls. J. Exp. Bot. 1999, 50, 1267-1280. [CrossRef]

95. Vishwanath, S.J.; Delude, C.; Domergue, F.; Rowland, O. Suberin: Biosynthesis, regulation, and polymer assembly of a protective extracellular barrier. Plant Cell Rep. 2015, 34, 573-586. [CrossRef] [PubMed]

96. Schnurr, J.; Shockey, J.; Browse, J. The acyl-CoA synthetase encoded by LACS2 is essential for normal cuticle development in Arabidopsis. Plant Cell 2004, 16, 629-642. [CrossRef]

97. Zhao, L.; Haslam, T.M.; Sonntag, A.; Molina, I.; Kunst, L. Functional overlap of long-chain acyl-CoA synthetases in Arabidopsis Plant Cell Physiol. 2019, 60, 1041-1054. [CrossRef]

98. Samuels, L.; Kunst, L.; Jetter, R. Sealing plant surfaces: Cuticular wax formation by epidermal cells. Annu. Rev. Plant Biol. 2008, 59, 683-707. [CrossRef]

99. Blacklock, B.J.; Jaworski, J.G. Substrate specificity of Arabidopsis 3-ketoacyl-CoA synthases. Biochem. Biophys. Res. Commun. 2006, 346, 583-590. [CrossRef]

100. Franke, R.; Briesen, I.; Wojciechowski, T.; Faust, A.; Yephremov, A.; Nawrath, C.; Schreiber, L. Apoplastic polyesters in Arabidopsis surface tissues-a typical suberin and a particular cutin. Phytochemistry 2005, 66, 2643-2658. [CrossRef]

101. Durst, F.; Nelson, D.R. Diversity and evolution of plant P450 and P450-reductases. Drug Metab. Drug Interact. 1995, 12, 189-206. [CrossRef]

102. Tijet, N.; Helvig, C.; Pinot, F.; Bouquin, R.L.; Lesot, A.; Durst, F.; Salaun, J.P.; Benveniste, I. Functional expression in yeast and characterization of a clofibrate-inducible plant cytochrome P-450 (CYP94A1) involved in cutin monomers synthesis. Biochem. J. 1998, 332, 583-589. [CrossRef]

103. Benveniste, I.; Bronner, R.; Wang, Y.; Compagnon, V.; Michler, P.; Schreiber, L.; Salaün, J.-P.; Durst, F.; Pinot, F. CYP94A1, a plant cytochrome P450-catalyzing fatty acid $\omega$-hydroxylase, is selectively induced by chemical stress in Vicia sativa seedlings. Planta 2005, 221, 881-890. [CrossRef] [PubMed]

104. Kosma, D.K.; Molina, I.; Ohlrogge, J.B.; Pollard, M. Identification of an Arabidopsis fatty alcohol: Caffeoyl-coenzyme A acyltransferase required for the synthesis of alkyl hydroxycinnamates in root waxes. Plant Physiol. 2012, 160, 237-248. [CrossRef] [PubMed] 
105. Soliday, C.; Kolattukudy, P.; Davis, R. Chemical and ultrastructural evidence that waxes associated with the suberin polymer constitute the major diffusion barrier to water vapor in potato tuber (Solanum tuberosum L.). Planta 1979, 146, 607-614. [CrossRef] [PubMed]

106. Iiyama, K.; Lam, T.B.T.; Stone, B.A. Phenolic acid bridges between polysaccharides and lignin in wheat internodes. Phytochemistry 1990, 29, 733-737. [CrossRef]

107. Graça, J.; Santos, S. Suberin: A biopolyester of plants' skin. Macromol. Biosci. 2007, 7, 128-135. [CrossRef]

108. Graça, J. Hydroxycinnamates in suberin formation. Phytochem Rev. 2010, 9, 85-91. [CrossRef]

109. Xin, A.; Herburger, K. Mini review: Transport of hydrophobic polymers into the plant apoplast. Front. Plant Sci. 2021, 11, 2059. [CrossRef]

110. Bird, D.; Beisson, F.; Brigham, A.; Shin, J.; Greer, S.; Jetter, R.; Kunst, L.; Wu, X.; Yephremov, A.; Samuels, L. Characterization of Arabidopsis ABCG11/WBC11, an ATP binding cassette (ABC) transporter that is required for cuticular lipid secretion. Plant J. 2007, 52, 485-498. [CrossRef]

111. Legay, S.; Guerriero, G.; André, C.; Guignard, C.; Cocco, E.; Charton, S.; Boutry, M.; Rowland, O.; Hausman, J.F. MdMyb93 is a regulator of suberin deposition in russeted apple fruit skins. New Phytol. 2016, 212, 977-991. [CrossRef]

112. Graça, J.; Schreiber, L.; Rodrigues, J.; Pereira, H. Glycerol and glyceryl esters of $\omega$-hydroxyacids in cutins. Phytochemistry 2002, 61, 205-215. [CrossRef]

113. Yeats, T.H.; Martin, L.B.; Viart, H.M.; Isaacson, T.; He, Y.; Zhao, L.; Matas, A.J.; Buda, G.J.; Domozych, D.S.; Clausen, M.H. The identification of cutin synthase: Formation of the plant polyester cutin. Nat. Chem. Biol. 2012, 8, 609-611. [CrossRef] [PubMed]

114. Girard, A.-L.; Mounet, F.; Lemaire-Chamley, M.; Gaillard, C.; Elmorjani, K.; Vivancos, J.; Runavot, J.-L.; Quemener, B.; Petit, J.; Germain, V. Tomato GDSL1 is required for cutin deposition in the fruit cuticle. Plant Cell 2012, 24, 3119-3134. [CrossRef] [PubMed]

115. Yeats, T.H.; Huang, W.; Chatterjee, S.; Viart, H.M.F.; Clausen, M.H.; Stark, R.E.; Rose, J.K. T omato C utin D eficient 1 (CD 1 ) and putative orthologs comprise an ancient family of cutin synthase-like (CUS) proteins that are conserved among land plants. Plant $J$. 2014, 77, 667-675. [CrossRef] [PubMed]

116. Philippe, G.; Gaillard, C.; Petit, J.; Geneix, N.; Dalgalarrondo, M.; Bres, C.; Mauxion, J.-P.; Franke, R.; Rothan, C.; Schreiber, L. Ester-crosslink Profiling of the Cutin Polymer of Wild Type and Cutin Synthase Tomato (Solanum lycopersicum L.) Mutants Highlights Different Mechanisms of Polymerization. Plant Physiol. 2016, 170, 807-820. [CrossRef] [PubMed]

117. Philippe, G.; Sørensen, I.; Jiao, C.; Sun, X.; Fei, Z.; Domozych, D.S.; Rose, J.K. Cutin and suberin: Assembly and origins of specialized lipidic cell wall scaffolds. Curr. Opin. Plant Biol. 2020, 55, 11-20. [CrossRef] [PubMed]

118. Jiang, Y.; Morley, K.L.; Schrag, J.D.; Kazlauskas, R.J. Different active-site loop orientation in serine hydrolases versus acyltransferases. ChemBioChem 2011, 12, 768-776. [CrossRef] [PubMed]

119. Yang, W.-L.; Bernards, M.A. Wound-induced metabolism in potato (Solanum tuberosum) tubers: Biosynthesis of aliphatic domain monomers. Plant Signal. Behav. 2006, 1, 59-66. [CrossRef]

120. Kligman, A.; Dastmalchi, K.; Smith, S.; John, G.; Stark, R.E. Building blocks of the protective suberin plant polymer self-assemble into lamellar structures with antibacterial potential. ACS Omega 2022, 7, 3978-3989. [CrossRef]

121. De Bruxelles, G.L.; Roberts, M.R. Signals regulating multiple responses to wounding and herbivores. CRC Crit. Rev. Plant Sci. 2001, 20, 487-521. [CrossRef]

122. Hildmann, T.; Ebneth, M.; Peña-Cortés, H.; Sánchez-Serrano, J.J.; Willmitzer, L.; Prat, S. General roles of abscisic and jasmonic acids in gene activation as a result of mechanical wounding. Plant Cell 1992, 4, 1157-1170.

123. Lulai, E.C.; Suttle, J.C. Signals involved in tuber wound-healing. Plant Signal. Behav. 2009, 4, 620-622. [CrossRef]

124. Barberon, M.; Vermeer, J.E.M.; De Bellis, D.; Wang, P.; Naseer, S.; Andersen, T.G.; Humbel, B.M.; Nawrath, C.; Takano, J.; Salt, D.E. Adaptation of root function by nutrient-induced plasticity of endodermal differentiation. Cell 2016, 164, 447-459. [CrossRef] [PubMed]

125. Mauch-Mani, B.; Mauch, F. The role of abscisic acid in plant-pathogen interactions. Curr. Opin. Plant Biol. 2005, 8, 409-414. [CrossRef] [PubMed]

126. Tuteja, N. Abscisic acid and abiotic stress signaling. Plant Signal. Behav. 2007, 2, 135-138. [CrossRef] [PubMed]

127. Soliday, C.L.; Dean, B.B.; Kolattukudy, P. Suberization: Inhibition by washing and stimulation by abscisic acid in potato disks and tissue culture. Plant Physiol. 1978, 61, 170-174. [CrossRef] [PubMed]

128. Kumar, G.M.; Lulai, E.C.; Suttle, J.C.; Knowles, N.R. Age-induced loss of wound-healing ability in potato tubers is partly regulated by ABA. Planta 2010, 232, 1433-1445. [CrossRef]

129. Suttle, J.C.; Lulai, E.C.; Huckle, L.L.; Neubauer, J.D. Wounding of potato tubers induces increases in ABA biosynthesis and catabolism and alters expression of ABA metabolic genes. J. Plant Physiol. 2013, 170, 560-566. [CrossRef]

130. Sandmann, G.; Böger, P. Inhibition of carotenoid biosynthesis by herbicides. In Target Sites of Herbicide Action, 1st ed.; CRC Press: Boca Raton, FL, USA, 2020; pp. 25-44.

131. Suttle, J.C.; Hultstrand, J.F. Role of endogenous abscisic acid in potato microtuber dormancy. Plant Physiol. 1994, 105, 891-896. [CrossRef]

132. Han, X.; Mao, L.; Wei, X.; Lu, W. Stimulatory involvement of abscisic acid in wound suberization of postharvest kiwifruit. Sci. Hortic. 2017, 224, 244-250. [CrossRef] 
133. Efetova, M.; Zeier, J.; Riederer, M.; Lee, C.W.; Stingl, N.; Mueller, M.; Hartung, W.; Hedrich, R.; Deeken, R. A central role of abscisic acid in drought stress protection of Agrobacterium-induced tumors on Arabidopsis. Plant Physiol. 2007, 145, 853-862. [CrossRef]

134. Lulai, E.C.; Suttle, J.C. The involvement of ethylene in wound-induced suberization of potato tuber (Solanum tuberosum L.): A critical assessment. Postharvest Biol. Technol. 2004, 34, 105-112. [CrossRef]

135. Denness, L.; McKenna, J.F.; Segonzac, C.; Wormit, A.; Madhou, P.; Bennett, M.; Mansfield, J.; Zipfel, C.; Hamann, T. Cell wall damage-induced lignin biosynthesis is regulated by a reactive oxygen species-and jasmonic acid-dependent process in Arabidopsis. Plant Physiol. 2011, 156, 1364-1374. [CrossRef] [PubMed]

136. Jin, J.; Tian, F.; Yang, D.C.; Meng, Y.-Q.; Kong, L.; Luo, J.; Gao, G. PlantTFDB 4.0: Toward a central hub for transcription factors and regulatory interactions in plants. Nucleic Acids Res. 2016, 45, D1040-D1045. [CrossRef] [PubMed]

137. Singh, K.B.; Foley, R.C.; Oñate-Sánchez, L. Transcription factors in plant defense and stress responses. Curr. Opin. Plant Biol. 2002, 5, 430-436. [CrossRef]

138. Seo, E.; Choi, D. Functional studies of transcription factors involved in plant defenses in the genomics era. Brief. Funct. Genom. 2015, 14, 260-267. [CrossRef]

139. Deluc, L.; Barrieu, F.; Marchive, C.; Lauvergeat, V.; Decendit, A.; Richard, T.; Carde, J.-P.; Mérillon, J.-M.; Hamdi, S. Characterization of a grapevine R2R3-MYB transcription factor that regulates the phenylpropanoid pathway. Plant Physiol. 2006, 140, 499-511. [CrossRef]

140. Mellway, R.D.; Tran, L.T.; Prouse, M.B.; Campbell, M.M.; Constabel, C.P. The wound-, pathogen-, and ultraviolet B-responsive MYB134 gene encodes an R2R3 MYB transcription factor that regulates proanthocyanidin synthesis in poplar. Plant Physiol. 2009, 150, 924-941. [CrossRef]

141. Almeida, T.; Menéndez, E.; Capote, T.; Ribeiro, T.; Santos, C.; Gonçalves, S. Molecular characterization of Quercus suber MYB1, a transcription factor up-regulated in cork tissues. J. Plant Physiol. 2013, 170, 172-178. [CrossRef]

142. Wei, X.; Mao, L.; Wei, X.; Guan, W.; Lu, W.; Xu, C. ABA stimulates wound suberization through antagonizing the MYB4-mediated transcriptional repressionof CYP86A1 and FAR in postharvest kiwifruit. Postharveset Biol. Technol. 2021, 172, 111354. [CrossRef]

143. Wang, C.; Wang, H.; Li, P.; Li, H.; Xu, C.; Cohen, H.; Aharoni, A.; Wu, S. Developmental programs interact with abscisic acid to coordinate root suberization in Arabidopsis. Plant J. 2020, 104, 241-251. [CrossRef]

144. Cohen, H.; Fedyuk, V.; Wang, C.; Wu, S.; Aharoni, A. SUBERMAN regulates developmental suberization of the Arabidopsis root endodermis. Plant J. 2020, 102, 431-447. [CrossRef] [PubMed]

145. Wei, X.; Mao, L.; Lu, W.; Wei, X.; Han, X.; Guan, W.; Yang, Y.; Zha, M.; Xu, C.; Luo, Z. Three transcription activators of ABA signaling positively regulate suberin monomer synthesis by activating cytochrome P450 CYP86A1 in kiwifruit. Front. Plant Sci. 2020, 10, 1650. [CrossRef] [PubMed]

146. Wahrenburg, Z.; Benesch, E.; Lowe, C.; Jimenez, J.; Vulavala, V.K.R.; Lü, S.; Hammerschmidt, R.; Douches, D.; Yim, W.C.; Santos, P.; et al. Transcriptional regulation of wound suberin deposition in potato cultivars with differential wound healing capacity. Plant J. 2021, 107, 77-99. [CrossRef] [PubMed]

147. Mahmood, K.; Zeisler-Diehl, V.V.; Schreiber, L.; Bi, Y.-M.; Rothstein, S.J.; Ranathunge, K. Overexpression of ANAC046 promotes suberin biosynthesis in roots of Arabidopsis thaliana. Int. J. Mol. Sci. 2019, 20, 6117. [CrossRef]

148. Yogendra, K.N.; Kumar, A.; Sarkar, K.; Li, Y.; Pushpa, D.; Mosa, K.A.; Duggavathi, R.; Kushalappa, A.C. Transcription factor StWRKY1 regulates phenylpropanoid metabolites conferring late blight resistance in potato. J. Exp. Bot. 2015, 66, 7377-7389. [CrossRef]

149. To, A.; Joubès, J.; Thueux, J.; Kazaz, S.; Lepiniec, L.; Baud, S. AtMYB92 enhances fatty acid synthesis and suberin deposition in leaves of Nicotiana benthamiana. Plant J. 2020, 103, 660-676. [CrossRef]

150. Legay, S.; Guerriero, G.; Deleruelle, A.; Lateur, M.; Evers, D.; André, C.M.; Hausman, J.-F. Apple russeting as seen through the RNA-seq lens: Strong alterations in the exocarp cell wall. Plant Mol. Biol. 2015, 88, 21-40. [CrossRef]

151. Zeier, J.; Ruel, K.; Ryser, U.; Schreiber, L. Chemical analysis and immunolocalisation of lignin and suberin in endodermal and hypodermal/rhizodermal cell walls of developing maize (Zea mays L.) primary roots. Planta 1999, 209, 1-12. [CrossRef]

152. Thomas, R.; Fang, X.; Ranathunge, K.; Anderson, T.R.; Peterson, C.A.; Bernards, M.A. Soybean root suberin: Anatomical distribution, chemical composition, and relationship to partial resistance to Phytophthora sojae. Plant Physiol. 2007, 144, $299-311$. [CrossRef]

153. Almeida, T.; Pinto, G.; Correia, B.; Santos, C.; Gonçalves, S. QsMYB1 expression is modulated in response to heat and drought stresses and during plant recovery in Quercus suber. Plant Physiol. Biochem. 2013, 73, 274-281. [CrossRef]

154. Capote, T.; Barbosa, P.; Usié, A.; Ramos, A.M.; Inácio, V.; Ordás, R.; Gonçalves, S.; Morais-Cecílio, L. ChIP-Seq reveals that QsMYB1 directly targets genes involved in lignin and suberin biosynthesis pathways in cork oak (Quercus suber). BMC Plant Biol. 2018, 18, 1-19. [CrossRef] [PubMed]

155. Wei, X.; Lu, W.; Mao, L.; Han, X.; Wei, X.; Zhao, X.; Xia, M.; Xu, C. ABF2 and MYB transcription factors regulate feruloyl transferase FHT involved in ABA-mediated wound suberization of kiwifruit. J. Exp. Bot. 2020, 71, 305-317. [CrossRef] [PubMed]

156. Wei, X.; Mao, L.; Wei, X.; Xia, M.; Xu, C. MYB41, MYB107, and MYC2 promote ABA-mediated primary fatty alcohol accumulation via activation of AchnFAR in wound suberization in kiwifruit. Hortic. Res. 2020, 7, 86. [CrossRef] [PubMed]

157. Singh, A.K.; Sharma, V.; Pal, A.K.; Acharya, V.; Ahuja, P.S. Genome-wide organization and expression profiling of the NAC transcription factor family in potato (Solanum tuberosum L.). DNA Res. 2013, 20, 403-423. [CrossRef] 
158. Olsen, A.N.; Ernst, H.A.; Leggio, L.L.; Skriver, K. NAC transcription factors: Structurally distinct, functionally diverse. Trends Plant Sci. 2005, 10, 79-87. [CrossRef]

159. Zhong, R.; Lee, C.; Ye, Z.-H. Functional characterization of poplar wood-associated NAC domain transcription factors. Plant Physiol. 2010, 152, 1044-1055. [CrossRef]

160. Puranik, S.; Sahu, P.P.; Srivastava, P.S.; Prasad, M. NAC proteins: Regulation and role in stress tolerance. Trends Plant Sci. 2012, 17, 369-381. [CrossRef]

161. Gong, L.; Zhang, H.; Gan, X.; Zhang, L.; Chen, Y.; Nie, F.; Shi, L.; Li, M.; Guo, Z.; Zhang, G. Transcriptome profiling of the potato (Solanum tuberosum L.) plant under drought stress and water-stimulus conditions. PLoS ONE 2015, 10, e0128041. [CrossRef]

162. Yang, P.; Chen, C.; Wang, Z.; Fan, B.; Chen, Z. A pathogen-and salicylic acid-induced WRKY DNA-binding activity recognizes the elicitor response element of the tobacco class I chitinase gene promoter. Plant J. 1999, 18, 141-149. [CrossRef]

163. Eulgem, T.; Rushton, P.J.; Robatzek, S.; Somssich, I.E. The WRKY superfamily of plant transcription factors. Trends Plant Sci. 2000, 5, 199-206. [CrossRef]

164. Hara, K.; Yagi, M.; Kusano, T.; Sano, H. Rapid systemic accumulation of transcripts encoding a tobacco WRKY transcription factor upon wounding. Mol. Gen. Genet. 2000, 263, 30-37. [CrossRef] [PubMed]

165. Cheong, Y.H.; Chang, H.-S.; Gupta, R.; Wang, X.; Zhu, T.; Luan, S. Transcriptional profiling reveals novel interactions between wounding, pathogen, abiotic stress, and hormonal responses in Arabidopsis. Plant Physiol. 2002, 129, 661-677. [CrossRef] [PubMed]

166. Rizhsky, L.; Liang, H.; Mittler, R. The combined effect of drought stress and heat shock on gene expression in tobacco. Plant Physiol. 2002, 130, 1143-1151. [CrossRef]

167. Shukla, V.; Han, J.P.; Cléard, F.; Lefebvre-Legendre, L.; Gully, K.; Flis, P.; Berhin, A.; Andersen, T.G.; Salt, D.E.; Nawrath, C. Suberin plasticity to developmental and exogenous cues is regulated by a set of MYB transcription factors. Proc. Natl. Acad. Sci. USA 2021, 118, e2101730118. [CrossRef] [PubMed]

168. Kamiya, T.; Borghi, M.; Wang, P.; Danku, J.M.; Kalmbach, L.; Hosmani, P.S.; Naseer, S.; Fujiwara, T.; Geldner, N.; Salt, D.E. The MYB36 transcription factor orchestrates Casparian strip formation. Proc. Natl. Acad. Sci. USA 2015, 112, 10533-10538. [CrossRef] [PubMed]

169. Liberman, L.M.; Sparks, E.E.; Moreno-Risueno, M.A.; Petricka, J.J.; Benfey, P.N. MYB36 regulates the transition from proliferation to differentiation in the Arabidopsis root. Proc. Natl. Acad. Sci. USA 2015, 112, 12099-12104. [CrossRef]

170. Gou, M.; Hou, G.; Yang, H.; Zhang, X.; Cai, Y.; Kai, G.; Liu, C.-J. The MYB107 transcription factor positively regulates suberin biosynthesis. Plant Physiol. 2017, 173, 1045-1058. [CrossRef]

171. Wang, T.; Tohge, T.; Ivakov, A.; Mueller-Roeber, B.; Fernie, A.R.; Mutwil, M.; Schippers, J.H.; Persson, S. Salt-related MYB1 coordinates abscisic acid biosynthesis and signaling during salt stress in Arabidopsis. Plant Physiol. 2015, 169, 1027-1041. [CrossRef]

172. Barberon, M. The endodermis as a checkpoint for nutrients. New Phytol. 2017, 213, 1604-1610. [CrossRef]

173. Franke, R.; Schreiber, L. Suberin—a biopolyester forming apoplastic plant interfaces. Curr. Opin. Plant Biol. 2007, 10, 252-259. [CrossRef]

174. Andersen, T.G.; Barberon, M.; Geldner, N. Suberization—the second life of an endodermal cell. Curr. Opin. Plant Biol. 2015, 28, 9-15. [CrossRef] [PubMed]

175. Roppolo, D.; De Rybel, B.; Tendon, V.D.; Pfister, A.; Alassimone, J.; Vermeer, J.E.; Yamazaki, M.; Stierhof, Y.-D.; Beeckman, T.; Geldner, N. A novel protein family mediates Casparian strip formation in the endodermis. Nature 2011, 473, 380-383. [CrossRef] [PubMed]

176. Li, P.; Yang, M.; Chang, J.; Wu, J.; Zhong, F.; Rahman, A.; Qin, H.; Wu, S. Spatial expression and functional analysis of Casparian strip regulatory genes in endodermis reveals the conserved mechanism in tomato. Front. Plant Sci. 2018, 9, 832. [CrossRef] [PubMed]

177. Pfister, A.; Barberon, M.; Alassimone, J.; Kalmbach, L.; Lee, Y.; Vermeer, J.E.; Yamazaki, M.; Li, G.; Maurel, C.; Takano, J. A receptor-like kinase mutant with absent endodermal diffusion barrier displays selective nutrient homeostasis defects. Elife 2014 3, e03115. [CrossRef]

178. Nakayama, T.; Shinohara, H.; Tanaka, M.; Baba, K.; Ogawa-Ohnishi, M.; Matsubayashi, Y. A peptide hormone required for Casparian strip diffusion barrier formation in Arabidopsis roots. Science 2017, 355, 284-286. [CrossRef]

179. Fujita, S.; De Bellis, D.; Edel, K.H.; Köster, P.; Andersen, T.G.; Schmid-Siegert, E.; Dénervaud Tendon, V.; Pfister, A.; Marhavý, P.; Ursache, R. SCHENGEN receptor module drives localized ROS production and lignification in plant roots. EMBO J. 2020, 39, e103894. [CrossRef]

180. Drapek, C.; Sparks, E.E.; Marhavy, P.; Taylor, I.; Andersen, T.G.; Hennacy, J.H.; Geldner, N.; Benfey, P.N. Minimum requirements for changing and maintaining endodermis cell identity in the Arabidopsis root. Nat. Plants 2018, 4, 586-595. [CrossRef]

181. Li, P.; Yu, Q.; Gu, X.; Xu, C.; Qi, S.; Wang, H.; Zhong, F.; Baskin, T.I.; Rahman, A.; Wu, S. Construction of a functional Casparian strip in non-endodermal lineages is orchestrated by two parallel signaling systems in Arabidopsis thaliana. Curr. Biol. 2018, 28, 2777-2786.e2772. [CrossRef]

182. Roppolo, D.; Boeckmann, B.; Pfister, A.; Boutet, E.; Rubio, M.C.; Dénervaud-Tendon, V.; Vermeer, J.E.; Gheyselinck, J.; Xenarios, I.; Geldner, N. Functional and evolutionary analysis of the CASPARIAN STRIP MEMBRANE DOMAIN PROTEIN family. Plant Physiol. 2014, 165, 1709-1722. [CrossRef]

183. Reyt, G.; Chao, Z.; Flis, P.; Salas-González, I.; Castrillo, G.; Chao, D.-Y.; Salt, D.E. Uclacyanin proteins are required for lignified nanodomain formation within Casparian strips. Curr. Biol. 2020, 30, 4103-4111.e4106. [CrossRef] 